\title{
DEMOCRACIA: ORIGEN, CONCEPTO Y EVOLUCIÓN SEGÚN ARISTÓTELES *
}

\author{
Osvaldo Guariglia \\ CONICET (Argentina)
}

RESUMEN. El propósito de este ensayo es examinar el origen y significado del término que designa el régimen, dêmokratía, y las instituciones que la formaron en su comienzo en la Grecia clásica. Examinaremos (1) el origen y el primitivo significado del término, luego pasaremos a reseñar (2) las instituciones de la democracia ateniense, tal como éstas fueron presentadas por ARISTÓTELES o uno de sus discípulos en la Constitución de los atenienses; después examinaremos (3) la clasificación de las diversas clases de democracia en ARISTÓTELES, siguiendo como él las expone en los libros centrales, iv-vi, de su Política; una vez establecidas las especies más importantes de ella, intentaremos exponer lo que a nuestro juicio son (4) los principios normativos de la democracia, de la república y de la oligarquía en ARISTÓTELES. El examen de la concepción de la democracia y de su régimen alternativo por antonomasia, la oligarquía, no estaría completo sin estudiar (5) la sedición y el cambio violento de régimen, así como los factores de su estabilidad intrínseca. Para concluir, abordaremos la cuestión central que, de un modo u otro, ARISTÓTELES dejó abierta a la posteridad: (6) ¿ «democracia»: gobierno de las leyes o gobierno de la masa?

Palabras clave: democracia, Grecia clásica, ARISTóteles, Constitución de Atenas, república, oligarquía, gobierno de las leyes, gobierno de la masa.

ABSTRACT. The aim of this essay is to study the origin and the meaning of the word dêmokratía, as well as of the regime referred to by it and its constituting institutions in Classical Greece. I will examine, first, (1) the origin and primitive meaning of the term. Then I will review (2) the institutions of Athenian democracy as they were expounded by ARISTOTLE (or by one of his disciples) in The Athenian Constitution (Athenaion Politeia). Thirdly, (3) I will analyze the classification of the five species of democracy as found in ARISTOTLE's Politics, books iv-vi. Once I had stipulated the description of these species, (4) I will turn to the Aristotelian conception of the normative principles of democracy, republic and oligarchy. The study of the notion of democracy and its traditional alternative regime, oligarchy, would not be complete without (5) exploring the causes of sedition and instability, to which both these regimes are prone. Finally, (6) I will treat the question ARISTOTLE left open for posterity: Is «democracy» the rule of law or the rule of the masses?

Keywords: democracy, classical greece, ARISTOTLE, Athenian Constitution, republic, oligarchy, rule of law, rule of the masses.

* Fecha de recepción: 9 de mayo de 2011. Fecha de aceptación: 13 de mayo de 2011. 


\section{INTRODUCCIÓN}

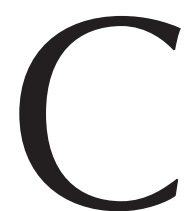

omenzar por el origen en el caso de la democracia no es un simple ejercicio de erudición, sino más bien un paso necesario en el esclarecimiento del largo camino que la institución que conocemos bajo ese nombre ha recorrido desde su inicio hace unos 2.500 años en Grecia. En primer lugar examinaremos (1) el origen y el significado del término dêmokratía; luego pasaremos a reseñar (2) las instituciones de la democracia ateniense, tal como éstas fueron presentadas por ARISTÓTELES o uno de sus discípulos en la Constitución de los atenienses; después examinaremos (3) la clasificación de las diversas clases de democracia en ARISTÓTELES, siguiendo como él las expone en los libros centrales, IV-VI, de su Política; una vez establecidas las especies más importantes de ella, intentaremos exponer lo que a nuestro juicio son (4) los principios normativos de la democracia y de la república en ARISTÓTELES. El examen de la concepción de la democracia y de su régimen alternativo por antonomasia, la oligarquía, no estaría completo sin estudiar (5) la sedición y el cambio violento de régimen, así como los factores de su estabilidad intrínseca. Para concluir, abordaremos la cuestión central que, de un modo u otro, ARISTÓTELES dejó abierta a la posteridad: (6) ¿«democracia»: gobierno de las leyes o gobierno de la masa?

\section{ORIGEN Y SIGNIFICADO DEL TÉRMINO «DÊMOKRATÍA»}

La etimología de la palabra «democracia» no da lugar a dudas, ya que sus dos componentes, los términos griegos dêmos y krátos, es decir: «pueblo» y «poder», forman parte de la definición nominal que se suele dar de la palabra misma. Más difícil, sin embargo, es precisar el momento en el que se creó el compuesto y establecer con claridad los matices de su significado originario. En efecto, por una parte, dêmos integra desde HOMERO distintas oposiciones que circunscriben su sentido: en la epopeya, se refiere a los soldados por oposición a los jefes y reyes; más adelante, designará a los inferiores con relación a quienes ostentan el poder, los dynatoí. Hacia fines del siglo VI a. C. el término en singular tomará una acepción colectiva que engloba al conjunto del pueblo, a todos los que forman parte de una misma comunidad. Ya en las elegías de SOLÓn, el legislador ateniense del siglo VI, encontramos, lado a lado, la acepción más restringida (el pueblo bajo) y la más general (el conjunto de los miembros de la comunidad) (vid.ArIst., Ath. Pol., XII, 1-2 = Solón, frgs. 5-6, Edmons). No es de extrañar, por tanto, que la primera inclusión de este significado en una tesis política esté provista por la sentencia de un filósofo, el frg. 44 de HERÁCLITO (DiELS-KrANZ): «el pueblo ( ho dêmos) debe luchar por la ley como por los muros». Esta conexión entre dêmos y nómos, la ley, se convertirá, como veremos, en una relación próxima a conceptual.

Por su parte, el término krátos está ligado desde HOMERO a la idea de «poder» en el sentido de «gobierno», que fue usado en paralelo al otro término que a partir del siglo VI se refiere por antonomasia a la institución, arché. De este último se derivan los términos compuestos con el sufijo -archía, en primer lugar el más antiguo de todos, monarchía (mounarchía en griego jónico), que desde el inicio estuvo conectado con otro término que a fines del siglo VII y comienzos del siglo VI describe un nuevo fenómeno 
de la vida política griega, la emergencia del týrannos como un gobernante con poder absoluto y apoyo de una nueva clase, opuesta a los eupatrídai (nobles), la población agraria, que es quien provee de los nuevos guerreros, la infantería hoplita ${ }^{1}$. La primera mención escrita de la distinción entre las tres formas de gobierno: monarquía, oligarquía y gobierno del pueblo está en tres versos de una oda de PíNDARO, compuesta hacia 470 a. C. (PínDARO, Pythia ii, 86-88), en la que «el pueblo» está representado por el ejército. A partir de las huellas dejadas en el lenguaje, se puede conjeturar, entonces, que la primera oposición estuvo dada entre el gobierno de uno, mon-archía, y el gobierno de pocos, olig-archía, como lo muestra la transición de una monarquía a una oligarquía de los eupatridas en Atenas, que fue una pauta seguida por otras ciudades (ARIST. Ath.Pol., frg. 2-5) ${ }^{2}$.

Más complejo es establecer con cierta precisión el momento en que fue acuñado el término dêmokratía y su referencia. Los primeros testimonios indirectos del uso de la palabra como un vocablo incluido en el habla de Atenas se sitúan entre el 470 y el 460 a. C. Entre esas fechas, en efecto, sitúan ahora los estudiosos la primera representación de las Suplicantes de Esquilo, que, según un papiro publicado en 1952, ganó el primer premio. El argumento de la tragedia, en breve resumen, narra la huida de Egipto de las hijas de Dánae a fin de evitar un casamiento sacrílego con sus primos, que las persiguen hasta Argos. Allí las recibe el rey, Pelasgo, a quien suplican protección y asilo. El rey vacila frente al riesgo de que esa decisión de lugar a una guerra con Egipto y, ante el apremio de las suplicantes y de su padre, anuncia que lo pondrá a resolución del pueblo. Terminada la asamblea a la que ha concurrido también Dánae, éste regresa para anunciar la decisión a sus hijas, quienes preguntan: «Dinos cómo ha sido proclamada la decisión final,/¿Hacia adónde se inclinó la mayoritaria mano gobernante del pueblo?» (dêmou kratoûsa kheír hópêi plêthýnetai, EsQ., Suppl., V., 603-4). Como se ha señalado con acierto, «la mano gobernante del pueblo» es una perífrasis de dêmokratía, ya que la votación en la Asamblea se hacía «a mano alzada», de modo que EsQUILO tendría en mente el nuevo término que, por su composición, era imposible de incluir siguiendo el metro del verso ${ }^{3}$.

El segundo testimonio indirecto también remite a la década del 470-60, y está provisto por la atribución del nombre Dêmokrátês a un ciudadano griego perteneciente a una de las familias más poderosas en Atenas, nacido aproximadamente en esa fecha, según el testimonio de un monumento funerario excavado en el año $1974^{4}$. De este modo, existen evidencias de que la división en tres regímenes según el número de los que poseen el poder, uno, pocos y la multitud, se ha convertido en un lugar común (PÍNDARO) hacia la misma época en que aparecen indicios de su posterior denominación. Cada uno

1 Cfr. Mossé, 1969: 11-25.

Cfr. RHODES, 1985: 76-79.

Cfr. EHRENBERG, 1950: 520-524.

${ }^{4}$ Democrates es el padre de Lysis —el personaje que da el título al diálogo homónimo de Platón (Lys. 204e-205c) - , perteneciente a una rica familia ateniense, que poseía una cabaña de caballos y participaba en los juegos píticos, ístmicos y nemeos. Según DAVIES (1971: 359-360), se trata del mismo Dêmokrátês que aparece nombrado por PlUTARCO como el amante de Alcibíades en los años 430 y siguientes, lo que haría de él el primer portador conocido de ese nombre, nacido entre el 470 y el 460 a. C. Tanto la existencia de Lysis como la de su padre, Demokrates, y las fechas aproximadas de sus vidas han sido posteriormente ratificadas por el descubrimiento del monumento funerario de Lysis en 1974 (STROUD, 1984: 355-60), en donde se lo identifica con los mismos nombres con los que lo presentó Platón: Lysis, hijo de Demokrates, del demo de Aixoneus. 
de los regímenes recibe, en efecto, un nombre contrastante con los otros dos, siguiendo una secuencia: mon-archía, olig-archía, dêmo-kratía. Sobre este último término, que inicia los compuestos con el sufijo -kratía, se habría creado posteriormente el vocablo aristo-kratía, que es atestiguado por primera vez por TUCíDIDES en un contexto que revela un origen preferentemente teórico y eufemístico del término (Hist. III, 82) ${ }^{5}$.

Hay pocas dudas de que el uso del término dêmokratía designaba y, simultáneamente, revelaba la existencia de una nueva realidad hasta entonces desconocida: la conexión entre el poder y sus participantes. Para quienes lo utilizaron al principio, el término tenía un claro tono peyorativo, lo que sugiere que era utilizado como un arma de combate por los miembros de la oligarquía que se enfrentaban al poder de las clases más bajas. Así lo demuestra el que seguramente es el texto más antiguo en el que el término es usado. Se trata de un texto apócrifo que fue transmitido junto con los escritos de JENOFONTE, actualmente identificado como Pseudo-Jenofonte o también como el Viejo Oligarca, que nos provee de un claro testimonio de la reacción antidemocrática provocada por la política de Efialtes, Pericles y sus sucesores. Este pequeño panfleto sobre el régimen político ateniense constituye un testimonio inapreciable de su funcionamiento hacia la segunda mitad del siglo v. Su autor es un abierto opositor al dominio del pueblo, al que considera inepto y corrupto pero, al mismo tiempo, inteligente y audaz en sus decisiones orientadas a mantener su hegemonía y a asegurar su predominio en el estado. No se trata sólo del primer testimonio del uso del término dêmokratía entendida como una forma estable de gobierno, con instituciones afianzadas y procedimientos acordes con éstas, sino también de la contraposición de aquélla con el otro régimen que, a lo ancho de toda la Hélade, era su alternativa, la oligarchía como el gobierno de los más ricos, más educados y más respetuosos de la ley (II, 17-20) ${ }^{6}$. La discusión acerca del dato más probable de su composición ha sido interminable y se ha movido entre dos fechas extremas de la segunda mitad del siglo v: el año 443, que ha ganado el apoyo de la mayoría de los comentaristas, como fecha más temprana, y el año 414 como fecha más tardía, que aún sostiene una minoría ${ }^{7}$. Desde el punto de vista de un análisis puramente político del texto, es claro que el autor pretendía participar en un debate en pleno desarrollo no solamente sobre la naturaleza de la democracia más extrema como nuevo fenómeno político, sino también sobre sus fortalezas y debilidades, así como su actual y futura estabilidad. Este aspecto del escrito sugiere una fecha más temprana, cuando las reformas introducidas por Efialtes (462 a. C.) y proseguidas por Pericles continuaban debatiéndose vivamente entre sus partidarios y detractores. (ARIST., Ath.Pol., 25-27, vid. más adelante).

El testimonio de Pseudo-Jenofonte y el uso más bien neutro de ambos términos, democracia y oligarquía, hecho por TuCíDIDEs, indican que éstos fueron utilizados con

5 Cfr. MeIER, 1970: 45-48, y 1972, 821, no encuentra diferencias entre los compuestos con -archía y los terminados con el sufijo -kratía. Contrariamente SEALEY, 1974: 273-90, sostiene que, en el caso de dêmokratía, la conexión con krátos acentuaba el carácter peyorativo del término.

${ }^{6}$ Cfr. Meier, 1972: 825-26; Sealey, 1974: 253-63; RaAflaub, 1983: 520-23; Cartledge, 2009: 63-64; 140-142

7 BOWERSOCK, 1967: 33-38, antepone a la más reciente edición del texto un largo estudio sobre la datación del mismo, y concluye que el año de la composición debe ser anterior a la guerra del Peloponeso, proponiendo el 443 como más probable. MATTINGLY, 1997: 352-57, contrariamente sigue sosteniendo el año 414 como la fecha más plausible. 
una carga negativa, no por sus propios adherentes, sino por sus respectivos adversarios. Como despiadadamente lo desvela el gran historiador, los líderes utilizan palabras benevolentes cuando proclaman sus propósitos: «una igualdad política (isonomía politikê) los líderes del pueblo y una aristocracia de los sabios (aristokratía sôphronos) los de la minoría», para luego perseguir sin escrúpulos sus propios intereses. Al atribuir categóricamente esta conducta a todos los políticos en su conjunto, él sustituye, irónicamente, los términos más crudos, «democracia» y «oligarquía», por los correspondientes eufemismos (Tuc., Hist., III, 82, 8). La acepción negativa de ambos vocablos se mantuvo hasta el siglo IV a. C. de modo parejo, pero comenzó a variar favorablemente en el caso de la democracia durante el siglo IV hasta convertirse en la ideología política dominante ${ }^{8}$. ¿En qué momento y por cuáles razones el significado de dêmokratía dejó de ser negativo y adquirió una serie de notas positivas, como «igualdad ante la ley» (isonomía), independencia y libertad para hablar y participar (eleuthería, isêgoría)? Las respuestas son conjeturales, pero sin duda se debieron a los cambios en la constitución política y en la composición social de la ciudad-estado que más adelante analizaremos. Por de pronto, existen claros testimonios que nos presentan, por primera vez, el tipo de poder de la dêmokratía de un modo favorable. En Hist. III, 80-81, HERÓDOTO narra que luego de la muerte de Cambises los persas deliberaron sobre la forma de gobierno que deberían adoptar para el futuro. En esas circunstancias, OTANES, partidario de la democracia, afirma que «cuando gobierna (árchei) la mayoría, recibe el más hermoso nombre de todos: isonomía [...]; las magistraturas se obtienen por sorteo, se rinde cuentas de los actos en el poder y todas las deliberaciones se hacen en común. [...] [En democracia] reside en el número el interés de todos».

El término utilizado por HERÓDOTO para designar el régimen democrático, isonomía, puede tener dos significados distintos según la raíz de la que derive el sufijo -nomía, del verbo némein («distribuir») o del sustantivo nómos («ley»). Si se toma como un compuesto de la primera, su sentido sería próximo a una «igualdad de partes», que implicaría una reivindicación de la distribución de las propiedades, en especial de la tierra, como implícita en el programa democrático. Si se considera, en cambio, como lo sugieren otros compuestos con el mismo sufijo —anomía, eunomía- que es un derivado de nómos, su sentido sería específicamente normativo e indicaría «igualdad de derechos» de todos los participantes de la misma comunidad política. Tal fue el reclamo central de los reformadores democráticos, desde CLísTENES en adelante, y éste es el sentido que destaca OTANES ${ }^{9}$.

Central en la exposición de HERÓDOTO es la oposición entre monarchía, oligarchía e isonomía (o, como también la llama, isêgoría) como los tres regímenes por antonomasia, que refleja el debate desarrollado durante todo el siglo v entre las tres formas canónicas de gobierno. Parte central de este debate era, sin duda, la enumeración de las ventajas y desventajas de cada régimen. Tal es lo que a continuación hacen los otros dos participantes del debate, uno partidario de la oligarquía y otro de la monarquía, al enumerar uno tras otro los defectos de los regímenes distintos al propugnado por ellos. Pero las notas mediante las que HERÓDOTO describe la democracia, tienen un énfasis especial. En efecto, el término mismo, isonomía, remite, como vimos, a una noción central en

8 Cfr. Sealey, 1974: 290-95; Hansen, 1999: 69-74.

9 Sobre los significados posibles del término, cfr. VLASTOS, 1947: 347-352, y HANSEN, 1999: 81-85. 
el pensamiento griego: nómos, la ley. Como lo señalé antes a propósito de HeRÁCLITO, la conexión entre el nómos, la pólis y el dêmos se convierte en una relación conceptual, permanente y constitutiva. El nómos es el lógos xynós que mantiene unido no solamente la ciudad humana, sino el cosmos. Se trata, pues, de una unidad divina, que es la que confiere permanencia y continuidad a las leyes humanas (fr. 114, DiELS-KRANZ) ${ }^{10}$. A este concepto central se le añade ahora un segundo elemento, que también tuvo su correlato en el pensamiento físico y cosmológico: la idea de isótês, de equilibrio entre las fuerzas contrapuestas, que aparece como una manifestación de la oculta isonomía (cfr. Alcmeón, fr. 4, DiELs-KranZ) ${ }^{11}$. De este modo el concepto de isonomía se extiende del mundo humano al mundo físico, al que impone su propia impronta: la unidad abstracta entre los derechos de cada uno de los miembros entendida como una relación de equilibrio en y por la cual cada uno conserva su propia naturaleza y en este sentido es justa, el ámbito de la Díke (cfr. Anaximandro, fr. 1, Diels-Kranz) ${ }^{12}$. Junto a isonomía y dêmokratía (VI, 43, 131) HERÓDOTO utiliza, por último, un tercer término como sinónimo del «gobierno del dêmos», isêgoría, a la que alaba como un «bien precioso» que ha transformado a los atenienses, convirtiéndolos en un pueblo vencedor y soberano $(\mathrm{V}, 78)$. En realidad, la palabra denomina un único derecho, el de hablar abiertamente en el ágora, como el derecho que funda la igualdad de los ciudadanos. En efecto, como luego lo expondrá detalladamente ARISTÓTELES, la igual participación en la Asamblea de los ciudadanos es el aspecto distintivo de toda forma de democracia ${ }^{13}$.

Justamente esta oportunidad de participación de «la muchedumbre» en el gobierno aparece como una garantía y al mismo tiempo como una demostración indiscutible de la eleuthería, es decir, de la independencia y soberanía de aquellos más desprovistos de recursos materiales e intelectuales dentro de la ciudad-estado. Será éste un rasgo especialmente destacado en la Oración Fúnebre que TuCíDIDES pone en boca de Pericles, como veremos luego. Ya EURíPIDES, en una tragedia estrenada en el último cuarto del siglo v a. C., Supplices, vv. 403 ss., hace que uno de los caracteres centrales, Teseo, líder de Atenas, responda así a un mensajero: «Errado vas desde el principio de tu discurso, extranjero, si buscas aquí un tirano. La ciudad no es gobernada (árchetai) por un solo hombre, sino que es libre. El pueblo (dêmos) gobierna por medio de sus magistrados anuales y no da el mando a los ricos; al contrario, el pobre tiene un derecho igual (íson)». Tras la respuesta del mensajero, que expresa un crudo elogio de la tiranía, Teseo ofrece el primer gran encomio de la democracia como régimen político de un gran escritor ateniense (vv. 429-446). Este elogio de la democracia y el elogio de Atenas como la ciudad-estado que no solamente se ha convertido en la defensora y propagadora de tal gobierno, sino que, precisamente por ello, impulsa una visión moral de la vida bumana que, siendo patrimonio común de toda la Hélade, es despreciada por los regímenes tiránicos, constituyen el tema central de esta pieza de EURÍPIDES que sorprende por su dominante tono político ${ }^{14}$.

Este aspecto bifronte de la democracia ateniense, mitad secular y mitad sagrada, nos vuelve a salir al paso en el más acabado elogio del régimen puesto por TuCíDIDES

\footnotetext{
10 Vid. KIRK, 1954: 48-55, y MONDOLFO, 1965: 136-140.

11 Cfr. Vlastos, 1947: 164-166; 1953: 361-365; 1964: 166-174.

12 Cfr. GuARIGLIA, 1966: 140-50.

13 Vid. Busolt, 1963: I, 304-5 con nota 4; RAaflaub, 1983: 518; OBER, 2008: 72-82.

14 Cfr. LESKY, 1963: 414-416; ZuNTZ, 1968: 305-325.
} 
en la boca de Pericles: «En las cosas públicas nos regimos por el temor de la ley, respetando a los magistrados que desempeñan en cada caso el gobierno y, por sobre todo, las leyes, en especial aquellas que ofrecen protección a las víctimas de la injusticia y a aquellas otras, que siendo no escritas, traen aparejada una vergüenza indiscutida cuando son lesionadas» (II, 37, 1-3).

A partir de este texto, la conexión conceptual entre «democracia», «igualdad de derechos» y «gobierno de la ley» aparece ya completamente consolidada en el pensamiento político griego. La isonomía, entendida como el derecho igual de todos a participar del poder, con las mismas prerrogativas y responsabilidades, pasa a expresar de modo permanente el contenido normativo de la democracia a tal punto que puede ser utilizado como su sinónimo ${ }^{15}$.

Tanto en el texto de EURÍPIDES como en el de Tucídides encontramos además una estrecha conexión que liga a la democracia con una cierta noción de la validez de leyes no escritas, que, sin embargo, deben ser respetadas. La nueva visión desacralizada, introducida por la Sofística, incorpora la antigua ley divina como una convicción moral que sostiene unida a la pólis. En otros términos, la democracia, en tanto heredera del viejo orden de los dioses, conserva un carácter ambiguo, a mitad de camino entre el orden sagrado y el profano. Diversos historiadores han subrayado esta compenetración del aspecto estatal y del religioso en la antigua ciudad-estado griega, la cual estaba unida en tanto comunidad al culto divino. En efecto, no había una autonomía de lo religioso con relación a lo político y esto estaba demostrado por la importancia del juramento que precedía cada acto institucional de la ciudad. Se trataba, como lo expresa el orador Licurgo (IV a. C.), del cemento mismo que mantenía unida a la ciudadanía por medio de la garantía divina: «Pues debéis saber esto, atenienses: es el juramento lo que mantiene unida la democracia. La república, en efecto, está compuesta de tres partes: el magistrado, el juez y el particular. Cada uno de ellos debe prestar juramento como garantía, y con razón» ${ }^{16}$.

A través de esta serie de textos que van desde la mitad del siglo $\mathrm{V}$ hasta la mitad del IV a. C. podemos seguir con precisión los matices de la coloración del término «democracia», que conservando siempre su fuerte contenido normativo, centrado en la noción de «igualdad ante la ley» y de «iguales derechos para todos los ciudadanos», va desplazando el aura religiosa que la rodea al comienzo por un compromiso intelectual y moral de tipo personal, que liga a cada ciudadano con un sistema de solidaridades institucionales. Como veremos más abajo, cada uno de estos motivos están conceptualmente sistematizados en el primer tratado filosófico-político de la historia del pensamiento occidental, la Política de ARISTÓTELES.

\section{LAS INSTITUCIONES DE LA DEMOCRACIA ATENIENSE}

Se ha afirmado acertadamente que «la historia de las ideas nunca es sólo la historia de las ideas; es también la historia de las instituciones, de la sociedad misma» ${ }^{17}$. Una

\footnotetext{
15 Vlastos, 1964: 177-183.

16 EHREnBerg, 1965: 90-92; HANSEN, 1999: 227; CARTLEdGe, 2009: 77-95.

17 Finley, 1985: 11.
} 
vez que hemos expuesto la evolución del significado del término, es necesario seguir más de cerca los pasos del desarrollo institucional hasta alcanzar la relativa estabilidad que tuvo la democracia en Atenas hacia fines del siglo $\mathrm{V}$ y durante casi todo el siglo IV a. C. ARISTÓTELES fue el primero que recogió bajo un mismo rubro la historia institucional de un estado y el examen sistemático del mejor régimen político. De un modo programático expone esta concepción metódica al final de la Ética Nicomáquea, cuando dice que, luego de estudiar lo expuesto por sus predecesores, «partiendo de las constituciones que bemos coleccionado, es necesario considerar qué cosas salvan o destruyen a las ciudades y cuáles a cada uno de los regímenes» (EN, X, 10, 1181b 15-19). Las biografías antiguas recogen dentro de las listas de las obras de Aristóteles una colección de 158 constituciones «ordenadas según el género: democráticas, oligárquicas, tiránicas (monárquicas), aristocráticas» (Diog. Laer. V, 27). Los numerosos fragmentos de esta colección obtenidos mediante las citas de otros autores fueron recopilados y ordenados de acuerdo con las ciudades, de los cuales los más numerosos eran los dedicados a Atenas y a Esparta ${ }^{18}$. En 1891 el British Museum publicó la primera edición del texto de tres papiros, adquiridos por el museo unos años antes, que contenía una gran parte de la Constitución de los atenienses, atribuida a ARISTÓTELES ${ }^{19}$. A partir de entonces poseemos la exposición, dividida en dos partes, de la constitución de Atenas: la primera, que va desde el inicio, cuyo primer capítulo está perdido, hasta el c. 41, narra la historia de los sucesivos cambios de la constitución desde el principio hasta el siglo IV; la segunda, que comprende los capítulos 42-69, expone sistemáticamente las magistraturas y poderes de la democracia de Atenas y la organización de éstos en el siglo IV a. C. ${ }^{20}$. Independientemente de si el texto de la Constitución provino de la mano del propio ARISTÓTELES o se redactó bajo su supervisión —un interrogante que también se presenta con las tres versiones de su Ética- ${ }^{21}$, no cabe duda de que la concepción de un desarrollo de los cambios de un régimen en sus sucesivas etapas hasta lograr una cierta estabilidad de su funcionamiento dentro de un marco normativo que se puede sintetizar en un conjunto consistente de leyes, es puramente aristotélica ${ }^{22}$.

En la recopilación final de los cambios de la constitución que se hace en el capítulo 41 se enumeran once transformaciones, desde el origen de Atenas, bajo la hegemonía de dos personajes semimíticos, Ion y Teseo, hasta la vigente en la época en que se está escribiendo el texto, aproximadamente en 327-26 a. C. ${ }^{23}$. De éstas las más importantes son, sin duda, la tercera, bajo la égida de Solón, «que se convirtió en el punto de partida y el principio de la democracia», la quinta, conducida por Clístenes, «que fue más democrática que la de Solón», y la séptima, «que Arístides puso en marcha y Efialtes completó, disolviendo el Consejo del Areópago; en ésta se dio frecuentemente ocasión para que los demagogos hicieran cometer errores a la ciudad a causa del poder sobre el mar» (Ath. Pol., 41,2). Antes de presentar una síntesis de los rasgos

18 Vid. ahora ARIST., Frag., 580a, 20 y ss. (GIGON).

19 La historia del origen del pequeño tratado, de sus posteriores ediciones y del debate en torno a su autenticidad puede consultarse en DAY-CHAMBERS, 1967: 1-3, y RHODES, 1985: 1-5.

${ }^{20}$ La autoría de Ath. Pol., es tema de un debate que sigue aún hoy sin resolver. Para conocer los argumentos a favor de ARISTÓTELES y, por el contrario, a favor de un anónimo discípulo, remito a DAY-CHAMBERS, 1967: 1-4, y a RHODES, 1985: 58-63, respectivamente.

$21 \mathrm{Al}$ respecto remito a GuARIGLIA, 1997b: 28-31.

22 Pace DaY-Chambers, 1967, 38-65; y Chambers, 1990: 75-82.

23 Vid. DAY-ChAmBERS, 1967: 195-199, para la fecha más probable de composición. 
más destacados de la democracia ateniense, expondremos brevemente los datos más relevantes que nos han llegado de cada una de las tres transformaciones principales, arriba señaladas.

La figura de Solón fue exaltada en el siglo IV como el creador de una democracia moderada, que sirvió de modelo y de consigna para la que regía en ese momento ${ }^{24}$. Como consecuencia de ello, se le atribuyeron al legislador leyes y normas constitucionales que fueron introducidas en época posterior, especialmente luego de la restauración de la democracia ateniense en 403 . De allí proviene la compleja tarea que exige poder desentrañar cuáles fueron realmente las medidas tomadas por el propio Solón y cuáles las que, creadas posteriormente, fueron puestas bajo su autoría ${ }^{25}$. ARISTÓTELES atribuye a Solón las reformas que sentaron las bases de la evolución posterior de la democracia ateniense hasta su fase más extrema hacia el fin del siglo V. El resumen que ofrece en el capítulo 9 enumera aquellas que a su juicio fueron las más importantes: «las tres normas más democráticas de la constitución de Solón parecen ser las siguientes: la primera y más importante es la prohibición de hacer préstamos dando como garantía el propio cuerpo [esto es, bajo pena de reducción a la esclavitud si no se devolvía el monto principal con los intereses]; luego, la admisión de presentar cargos contra quienes hayan cometido injusticias para todo aquel que desease hacerlo, y la tercera, que se considera aquella que más fortaleció al pueblo, es la apelación [de los fallos de los magistrados y probablemente del Areópago] al tribunal popular, ya que, cuando el pueblo es dueño del guijarro [con el que se vota] se convierte en el dueño de la constitución» (Ath. Pol., 9, 1). A esta lista agrega, en el capítulo siguiente, una aclaración importante: «se admite que éstas fueron las medidas democráticas que Solón promovió mediante sus leyes. Sin embargo, antes de haber aprobado esta legislación [nomothesía], había llevado a cabo la cancelación de las deudas [seisachtheía] y después la ampliación de las medidas, de los pesos y del dinero [posiblemente, una forma de devaluación]» (Ath. Pol., 10, 1) ${ }^{26}$. Por último, tanto en la Política como en la Constitución de los atenienses, Solón es presentado como el creador de una forma de constitución mixta, compuesta por un poder oligárquico, el Consejo del Areópago, por la elección de los magistrados, que al no ser por simple sorteo es considerada aristocrática, y por una justicia popular elegida por un sorteo abierto a todas las clases, mediante la cual el pueblo retiene su poder soberano. A esta división de poderes se agrega la estratificación timocrática de las clases de acuerdo a sus ingresos, establecidos en la cantidad de medidas sólidas y líquidas que obtenían anualmente de sus haciendas. La clase más alta era la que no ganaba menos de quinientas medidas (pentakosiomédimnoi), los caballeros (bippê̂s), trescientas medidas, los labradores (zeugittai), doscientas medidas, y los jornaleros (thêtes), por debajo de éstas. Los miembros de las tres primeras clases podían ser elegidos para las magistraturas: los nueve arcontes, los administradores, tesoreros, representantes del es-

24 Cfr. HANSEN, 1999: 298-304.

25 Vid. el análisis de DAY-CHAMBERs, 1967: 71-75.

26 Todos estos datos están sujetos a un constante examen crítico, que se mueve entre un completo escepticismo con respecto a la verosimilitud de las fuentes utilizadas por ARISTÓTELES y una moderada confianza en la solidez de las mismas. Doy a continuación una bibliografía abreviada de la discusión desde principios del siglo pasado: De SANCTIS, 1912: 193-259; HAMmOND, 1940: 71-83; VlaSTOS, 1946: 65-83; HAMMOND, 1961: 76-98; DAY-CHAMBers, 1967: 66-100; MANVILle, 1980: 213-221; RHODES, 1985: 136-179; CHAMBERS, 1990: 159-193; Harris, 2002: 415-430, y Wallace, 2007: 49-82 (el importante libro de A. J. Domínguez MonEdERO, Solón de Atenas, Barcelona, Crítica, 2001, no me fue accesible). 
tado en las ventas, etc.; los thêtes, en cambio, podían participar solamente en la Asamblea y en los jurados populares (ARIST., Pol., II, 21, 1273b, 38-21; Ath. Pol., 7, 1-3).

La situación de Atenas hacia el fin del siglo VI se acercaba a la de una guerra civil, en la que un reducido grupo de antiguas familias aristocráticas, los eupatridas, poseían la totalidad del campo llano y fértil en torno a la ciudad, contra la muchedumbre de pequeños campesinos, dueños de sus propios fundos de tierra rocosa en la parte montañosa del Ática. Bastaba una mala cosecha para forzar a éstos a endeudarse, contrayendo hipotecas que imponían la sexta de parte del producto (bektêmórioi) como rédito anual (un 16,66 por 100), y a quienes no poseían tierras como garantía, a dar el propio cuerpo como seguro del préstamo, que a muchos de ellos les valió ser apropiados como esclavos. Las reformas de Solón, al liberarlos de las deudas y al prohibir la esclavitud de atenienses, creó una nueva comunidad de ciudadanos, que se completó con la eliminación de los privilegios políticos de la vieja oligarquía gentilicia y el alumbramiento de una nueva timocracia, basada exclusivamente en la riqueza. Sin duda, tanto la revuelta contra la oligarquía tradicional como la puesta en práctica de las nuevas normas e instituciones no solamente presuponen sino que hacen necesaria la existencia de una nueva fuerza dispuesta a apoyarlas, eventualmente con las armas. A esta nueva fuerza está unida la aparición de los labradores como clase política y de su contraparte militar, la falange de los hoplitas, que ellos conformaban. El ciudadano modelo es a partir de entonces un campesino medio que vive sobre la base de un fundo, (klêros), el cual, por pequeño que fuese, era suficiente para proveerlo de su subsistencia. La posesión de éste era la condición indispensable para formar parte del grupo social privilegiado de ciudadanos-guerreros que podían suplir su propio armamento y combatir como infantes pesadamente armados en formación cerrada, lo que exigía mantener una coordinación táctica de todas las filas y, por ende, un largo entrenamiento. (ARIST., Pol., IV, $13,12976,1-28)^{27}$. Apoyándose sobre esta nueva clase, a la que Solón «veía osada y en efervescencia por la eliminación de las deudas» (PLUT., Solon, 19, 1), él creó un nuevo Consejo para oponer al del Areópago, que, a diferencia de este último, se reclutaba directamente de las cuatro tribus, que aportaban, cada una, cien miembros escogidos (ARIST., Ath. Pol., 8, 4). Su función consistía en emitir dictámenes que habilitaban los temas para que los tratase posteriormente la Asamblea ${ }^{28}$. No es sorprendente que, como sostiene también ARISTÓTELES, esta democracia de labradores hoplitas, es decir, de la clase media, fuera asumida más tarde como un modelo a seguir por los adversarios de los regímenes populares más extremos hacia el fin del siglo V y durante el siglo IV.

Totalmente eclipsado por Solón hasta caer casi en el olvido a partir de la restauración democrática del 403 en adelante, Clístenes había sido considerado en todo el

27 Para la importancia de los hoplitas en las revoluciones del siglo vi, vid. DetiEnNe, 1968: 119-42; VIDAL-Naquet, 1968: 161-81; Mossé, 1968: 220-29; Austin-Vidal-Naquet, 1972: 65-77; CarTLEdGE, 1977 : 18-24 y SALMON, 1977: 93-101. Para una evaluación global de las reformas de Solón y de sus consecuencias para la formación de la democracia, vid. ahora WALLACE, 2007: 60-82.

28 La creación de este Consejo de los cuatrocientos ha sido rechazada por varios historiadores (DE SANCTIS, 1912: 251; DAY-CAMBERS, 1967: 200-201, etc.). Sus argumentos, sin embargo, están basados sobre improbables sospechas contra la afirmación bien documentada de su existencia por parte de ARISTÓTELES y de Plutarco, Solon, 19, 1. La inexistencia de este Consejo, por lo demás, haría incomprensible la resistencia del Consejo, que no puede ser el Areópago, y del pueblo a Isagoras y Cleomenes que antecede a las reformas de Clístenes (ArIst., Ath.Pol., 20, 3). Para una discusión del asunto, vid. Rhodes, 1985: 153-54 y $543-44$. 
siglo $\mathrm{V}$ el verdadero fundador de la democracia ateniense y el autor de las radicales reformas que establecieron sus sólidas bases ${ }^{29}$. Él era miembro de una familia de eupatridas, los Alcmeónidas, que habían sido alcanzados por una acusación de perjurio contra uno de sus antepasados, y que a raíz de eso tuvieron que afrontar posteriormente condenas y exilios ${ }^{30}$. Nos quedan dos relatos paralelos de la historia de los sucesos de los años 508/7 que desencadenaron las reformas introducidas a la constitución vigente de Solón a los Pisistrátidas, el de Heródoto (V, 66-73) y el de la Constitución de los atenienses (20-21), que depende en larga medida del primero ${ }^{31}$. A continuación doy la que parece ser la secuencia más probable de los hechos, reconstruida a partir de ambos relatos: 1) luego de que el último Pisistrátida se hubiera retirado, se enfrentaron dos facciones rivales entre los clanes oligárquicos, uno, afín a los derrotados tiranos, dirigido por Iságoras y el otro que era conducido por Clístenes con el apoyo de sus numerosos familiares. En la elección de arconte Iságoras derrotó a Clístenes, porque volcó en su favor a la mayoría de las confraternidades (betairíai) de las grandes familias que dominaban las instituciones. 2) Como consecuencia, Clístenes buscó el apoyo del pueblo con la promesa de reformar la constitución a favor de éste. Hay coincidencia entre los historiadores sobre el método utilizado por Clístenes para promover estas reformas, que no le habían sido encargada en calidad de legislador, como había ocurrido con Solón. Se trataron de propuestas hechas directamente ante la Asamblea y aprobadas por mayoría, es decir, bajo la forma de decretos. 3) Iságoras, alarmado ante el avance de Clístenes, llamó en su ayuda al rey de Esparta, Cleomenes, al que estaba ligado por lazos de hospitalidad, quien ingresó a Atenas con un pequeño contingente de soldados y exigió expulsar a los Alcmeónidas por ser una familia condenada por perjura. 4) Clístenes se retiró secretamente y Cleomenes, luego de expulsar a 700 familiares de aquél, intentó disolver el Consejo e instaurar otro formado por trescientos partidarios de Iságoras. El Consejo resistió el embate y el pueblo se levantó en masa contra Iságoras y Cleomenes, quienes huyeron con su tropa a la Acrópolis. Allí los sitiaron durante dos días, hasta que al tercero Cleomenes y los suyos solicitaron una tregua y se les permitió retirarse del Ática. 5) El pueblo envió emisarios a Clístenes, quien regresó junto a los otros exiliados: «habiendo tomado el control de los asuntos el pueblo, Clístenes fue su conductor y la principal cabeza de los populares» (Ath. Pol., 20, 4) ${ }^{32}$.

Antes de pasar al examen de las reformas que Clístenes puso en práctica es necesario despejar una ambigüedad en la narración de los acontecimientos cuya interpretación incide directamente en la comprensión del carácter de la democracia clisteniana. El término «pueblo» (dêmos) que he traducido literalmente más arriba, dejándolo en bastardilla, puede referirse en este contexto a una de las dos clases inferiores de acuerdo a la jerarquía instaurada por Solón y mantenida desde entonces, los zeugîtai, esto es, los campesinos medios, o los thêtes, es decir, los simples jornaleros, artesanos, etc.

29 Cfr. Wilamowitz-MoELlendorF, 1893: II, 144-45.

30 Vid. la historia de la familia en DAVIES, 1971: 370-75.

31 El análisis de los dos relatos y sus conexiones fue expuesto detalladamente por WADE-GERY, 1933: 17-29, que sigue siendo la base de los trabajos posteriores. Vid. ahora, DAY-CHAMBERS, 1967: 101-120; WILL, 1972: 63-76; RHODES, 1985: 240-66; HANSEN, 1999: 34-37, 296-300; CHAMBERS, 1990: 220-234; y más recientemente el contrapunto sobre las reformas de Clístenes y el origen de la democracia de RAAFLAUB, OBER Y WALLACE, 2007: 76-154.

32 La cronología de los acontecimientos es la que reconstruyó SEAGER, 1963: 287-289, que siguen también RHODES, 1985: 244-45, y CHAMBERS, 1990: 221-23. 
En la Política, al comentar cómo se debe proceder para diseñar una constitución popular con hegemonía del pueblo llano, Aristóteles restringe su referencia claramente al afirmar «es necesario establecer un límite para el aumento de los ciudadanos de la masa (tò plêthos, la clase inferior), que sea el punto en el que esta masa supere pero no sobrepase en mucho la suma de la clase superior y de los del medio» (VI, 4, 1319b, 12-14). En la Constitución de los atenienses, en cambio, el término está usado para oponer nítidamente la oligarquía pro-espartana con el resto del pueblo. ¿Cómo estaba constituido ese «resto»? Hay dos interpretaciones posibles: a) que ARISTÓTELES utilice aquí el término restringido a la clase inferior, como en la Política - a la que un autor llama en este caso «subhoplitas»-; o b) que se trate de la confluencia de los thêtes y los zeugîtai, pero bajo la hegemonía y la conducción de estos últimos ${ }^{33}$. Tras esta distinción se enfrentan dos concepciones posibles del surgimiento de la democracia: como la súbita irrupción de una nueva clase o como la culminación de un proceso gradual de reformas, que se inició con Solón, se fue gestando en forma latente bajo los Pisistrátidas, y se terminó de conformar con la revuelta que llevó a Clístenes al poder. Hay un dato que apunta a favor de esta última visión de todo este largo camino hacia la democracia durante todo el siglo vI: el rol determinante que desempeñó la milicia contra la oligarquía conducida por Iságoras y el contingente espartano de Cleomenes. No es posible imaginar que un contingente como ése, disciplinado y aguerrido, acompañado de ciudadanos atenienses de la oligarquía, que como tales poseían una experiencia de combate tradicional en hombres hambrientos de honores, entrara tan rápidamente en pánico y huyera en desorden a refugiarse en un sitio, la Acrópolis, donde era imposible resistir sin logística previa, si no hubiese tenido frente a sí a un cuerpo armado no solamente superior en número, sino también equivalente a ellos en armamento y disciplina estratégica. En otros términos, quienes cortaron el nudo gordiano fueron los hoplitas atenienses, provenientes de esa clase media, los ex hektêmórioi liberados por Solón de sus deudas, que entretanto habían progresado, enriqueciéndose silenciosamente bajo la tiranía de los Pisistrátidas, e integrándose al estado como la nueva fuerza militar, decisiva para defenderlo o para expandirlo (ARIST., Pol., VI, 4, 1318b, 11-20). No se excluye, por cierto, que también se armaran y se agregaran a la lucha quienes, aún sin pertenecer formalmente a las falanges hoplitas, fuesen ocasionales contingentes auxiliares, los «subhoplitas», pero la cuestión central reside en descubrir qué fuerza hubiera podido estar en condiciones de infundir un temor tan grande como para hacer huir sin enfrentarse una tropa profesional, disciplinada y armada, como la de los espartanos, por poco numerosa que ésta fuese. La hora de los thêtes aún no había llegado.

Las reformas introducidas por Clístenes han sido comparadas con las que hizo la Revolución Francesa por las profundas transformaciones sociales y políticas que conllevaron. Se trató, en ambos casos, de la sustitución de una organización tradicional, basada en conexiones gentilicias y religiosas, por otra puramente civil, basada en una redistribución del territorio y en la creación de nuevas agrupaciones seculares que suplantaban a las antiguas ${ }^{34}$. Clístenes sustituyó las cuatro tribus existentes por diez

33 La alternativa $a$ ) es defendida por OBER, 2007, 86-104; la $b$ ) es sostenida por WALLACE, 2007: 76-82 y RAAFLAUB, 2007: 142-154.

${ }^{34}$ La bibliografía sobre las reformas de Clístenes es extensa y controvertida. Cito a continuación los trabajos más importantes para la interpretación del texto de Ath. Pol., 21-22: Wilamowitz-Moellendorf, 1893: 145-168; De SANCtis, 1912: 333-360; Wade-GerY, 1933: 25-29; DAY-Chambers, 1967: 107-120; Will, 
nuevas, formadas de la siguiente manera: cada tribu (phylê) estaba compuesta por tres tercios (trittýes), de los cuales diez pertenecían a la ciudad y sus alrededores, diez a la costa y diez al interior del Ática. Cada tribu debía tener un tercio de cada una de las regiones, asignado a esa tribu por sorteo, de modo que cada tribu estaba compuesta por tres tercios de tres regiones diferentes. Los demos fueron, a su vez, distribuidos entre los tercios y constituyeron a partir de entonces la sección oficial de inscripción del ciudadano y parte de su nombre, a fin de evitar el patronímico y sustituirlo por el demo del que provenía. Cada demo elegía un demarco, que presidía una asamblea del demo correspondiente, la cual constituía una célula del nuevo orden político. El Consejo de los cuatrocientos fue, a su turno, sustituido por uno nuevo, formado por quinientos ciudadanos que provenían de las diez tribus, a razón de cincuenta por cada tribu. Los nuevos ciudadanos, antiguos metecos y esclavos, fueron de este modo incorporados a los nuevos demos sin que sus patronímicos pudiesen ser causa de discriminación por su origen no ateniense (ARIST., Ath. Pol., 21, 4 y Pol., III, 2, 1275b, 35-37). Tal reorganización tuvo necesariamente que seguir un designio previo del reformador, que si no coincide exactamente con el que ARISTÓTELES le atribuye en la Política, debió de haber sido muy próximo a éste: «para que se mezclen al máximo todos entre sí y se disuelvan los vínculos anteriores» (VI, 4, 1319b, 25-27). No hay duda de que las reformas fueron el inicio del régimen que con justicia fue conocido y nombrado como isonomía, es decir, no solamente «igualdad de todos bajo la ley», sino también, «promoción de la igualdad mediante la ley» ${ }^{35}$.

Sobre la última reforma que la Constitución de los atenienses incluye en el resumen final, es decir, la séptima «que Arístides puso en marcha y Efialtes completó, disolviendo el Consejo del Areópago» (Ath. Pol., 41, 2), estamos mucho menos informados. Por esa razón, tanto la figura de Efialtes como el contenido de sus reformas sigue siendo un tema de continuo debate entre los historiadores. Según el testimonio más fidedigno e importante que nos queda (ARIST., Ath. Pol., 25, 1-2), Efialtes en el año 462 le quitó al Areópago unas funciones claves que venía desempeñando y las entregó al Consejo de los quinientos, a la Asamblea y a los jurados populares. De qué funciones previas se trataba, no está especificado y es el tema central del disenso entre los intérpretes ${ }^{36}$. El resultado fue, sin embargo, claro: las funciones políticas, tales como la salvaguardia de la constitución y la rendición de cuentas de los magistrados, fueron transferidos al Consejo de los quinientos y a los tribunales populares. El Areópago quedó limitado a un tribunal penal que juzgaba los homicidios de ciudadanos atenienses y a ejercer funciones religiosas, como el cuidado de los olivos sagrados. Más tarde, durante el siglo IV, a compás de la restauración de una democracia más moderada, este Consejo retomó algunas de sus antiguas funciones, sin recobrar nunca su anterior poder ${ }^{37}$.

A partir de entonces se sucedieron leyes que acentuaron el carácter popular de la democracia del siglo v, como la introducción de dietas a los miembros de los tribunales

1972: 66-76; BENGSTON, 1977: 143-145; ANDREWES, 1977: 241-248; RHODES, 1985: 248-266; CHAMBERS, 1990 :

224-238, y HANSEN, 1999: 34-35 y 46-49.

35 VLASTOS, 1953: 356-57.

36 Vid. Wilamowitz-Moellendorf, 1893: II, 92-102 y 186-200; SEALEy, 1964: 11-22; RHODES, 1985 :

311-24; más recientemente CHAMBERS, 1990: 257-260, y RIHLL, 1995: 87-98.

37 HANSEN, 1999: 287-290. 
y más tarde de la Asamblea, etc., a fin de asegurar la asistencia a ella, pero su marco institucional estaba ya fijado. Las instituciones que la definían estaban conformadas por el conjunto de todos los hombres mayores de dieciocho años a quienes se les había reconocido el derecho de ciudadanía, derecho que a partir de una ley promovida en 451 por Pericles, quedó limitado a aquellos cuyos dos padres eran atenienses. Los ciudadanos eran no sólo los miembros de las clases más antiguas y acaudaladas, sino también aquellos otros que pertenecían al estamento de los más desposeídos: artesanos, pequeños comerciantes, campesinos, marineros, etc. (JENOF., Memorab., III, 6-7) ${ }^{38}$. La Asamblea del pueblo (ekklêsía) era el órgano soberano de gobierno, tanto legislativo como administrativo, que se reunía al menos diez veces al año, aunque a las sesiones principales podían añadirse hasta tres más suplementarias en cada mes, según las exigencias del momento. De ella tenían derecho a participar de modo directo todos los ciudadanos atenienses, cuyo número en la época de Pericles puede calcularse entre 35.000 y 40.000 hombres. La participación efectiva, sin embargo, debía de ser mucho menor, ya que para determinadas decisiones de gran importancia se exigía un quórum mínimo de 6.000 ciudadanos, de lo que se puede inferir que la concurrencia habitual podía ser menor ${ }^{39}$. Las votaciones se hacían a mano alzada sobre cualquier asunto puesto a consideración por el Consejo de los quinientos (Boulê), que debía sesionar con anterioridad a fin de preparar los proyectos que constituirían el orden del día de la Asamblea. Este Consejo, a su vez, estaba formado por 50 miembros sorteados de cada una de las diez tribus en que estaba dividido el dêmos y constituía el único cuerpo permanente de duración anual en la democracia ateniense. La Asamblea, en cambio, variaba completamente de convocatoria en convocatoria, sin que existieran aparatos políticos, tales como los partidos, o una burocracia estatal permanente ${ }^{40}$. Es claro que ningún líder político en esas circunstancias tenía garantizada la aprobación de su propuesta ni la continuidad de su política, sino que debía ganársela de sesión en sesión y exponerse permanentemente a una denuncia de llevar a cabo una acción de ilegalidad, (graphê paranómôn), es decir, por promover un proyecto contrario a la legislación ya existente $^{41}$.

La Asamblea tenía la potestad de decidir tanto sobre leyes generales (nómoi) como sobre decretos, (psêphisma), cuyo contenido remitía a cuestiones particulares, una distinción de principio que estaba, empero, lejos de ser siempre acatada (ARIST., Pol., IV, 4, 1292a, 18-39) ${ }^{42}$. En ambos casos, sus resoluciones eran soberanas y no había ninguna posibilidad de revisión constitucional por un poder judicial independiente. Los tribunales populares dependían, en efecto, de la Asamblea y sus miembros eran sorteados de entre sus componentes, de modo que cualquier acción de un líder político podía dar lugar a una denuncia ante la justicia y una subsiguiente condena irrevocable. La consecuencia directa de esta organización política era la completa ausencia

38 Cfr. Kluwe, 1976: 303-305.

39 Cfr. Glotz, 1953: 180-181; WILl, 1972: 449-450; HANSEN, 1999: 130-131 sostiene, a partir de las dimensiones del Pnyx, que éste admitía 6.000 personas sentadas, y que ese número de asistentes debía de ser el quórum normal.

40 Cfr. FINLEY, 1974b: 10-13; 1985, 52-55.

41 Cfr. WILl, 1972: 452-453; RhODES, 1985: 544-545; HANSEN, 1999: 205-211.

42 Para el respeto por la distinción nómos-psêphisma, vid. Glotz, 1953: 192-194; EHRENBERG, 1965: 68-70, y RHODES, 1985: 329 y 512-513. 
de derechos subjetivos absolutamente salvaguardados, a diferencia de como ocurre en el ordenamiento jurídico moderno ${ }^{43}$. La contienda entre adversarios asumía consecuentemente una inevitable ferocidad. Se trataba de una lucha sempiterna a todo o nada entre los líderes opuestos, que no reconocía tregua alguna hasta la total derrota y destrucción del adversario, sea mediante el ostracismo o, más drásticamente aún, la revuelta y las consecuentes condenas a prisión o muerte ${ }^{44}$. La consigna de «beneficio para mis amigos y daño para mis enemigos» no sólo era abiertamente admitida en la sociedad griega, sino que era también legalmente usada en los alegatos ante los tribunales como algo sobreentendido ${ }^{45}$. De ahí que la división «amigo-enemigo» se extendiera de la lucha política al enfrentamiento privado e involucrara a los miembros de una misma confraternidad, (betairía), originalmente de carácter social pero a partir de las reformas de Clístenes decididamente volcada a la acción política ${ }^{46}$. La lucha facciosa se llevaba a cabo con un desmesurado encono que no respetaba límites entre lo público y lo privado ni se detenía en consideraciones de parcialidad tanto en el manejo de la Asamblea como de los tribunales populares con el fin de alcanzar el éxito.

Dados estos rasgos constitutivos de la democracia directa y en general de todo régimen político de la ciudad-estado antigua, no resulta una sorpresa que estuviera en todos ellos siempre latente el peligro de la revuelta (stasis), el cambio mediante la toma sangrienta del poder y, en los casos extremos, la guerra civil que podía ser extremadamente cruenta. ARISTÓTELes dedica el libro V de la Política al estudio de este fenómeno y a precisar sus causas, que, como señala en el primer capítulo, son intrínsecas a cada régimen político $(1301 a, 34-1301 b, 12)$. Retornaremos a este tema después de considerar su análisis de la democracia.

\section{LA CLASIFICACIÓN DE LAS DIVERSAS CLASES DE DEMOCRACIA EN ARISTÓTELES}

En una exposición que se transformó en un modelo para la filosofía política posterior, Aristóteles presenta en primer lugar los fundamentos teóricos de los regímenes políticos para mostrar luego sus divisiones y peculiaridades: «la amistad y la justicia se dan, a lo que parece, en torno a las mismas personas y a las mismas circunstancias: en toda comunidad se pone de manifiesto, efectivamente, la existencia de una cierta especie de justicia y de amistad» (EN, VIII, 11, 1159b, 25-28). Por «comunidad» (koinônía) ARISTÓTELES entiende la existencia de una agrupación de individuos en la cual ninguno está sujeto al servicio de otro como si fuese su instrumento, (es decir, del modo en que el esclavo está sujeto a su amo), sino que todos los participantes de ella tienen un interés común ${ }^{47}$. Las diversas especies de comunidad, por ejemplo la doméstica, son partes de la comunidad política, que es la que abarca a todas ellas. Tomando como criterio la manera en que se distribuye ese «interés común», ARISTÓTELES divide

43 Will, 1972: 455-458; CARTLEDGE, 2009: 13 ss.; más dubitativo es HANSEN, 1999: 130-131, especialmente para el siglo IV.

${ }_{44}$ Finley, 1974b: 21-23; 1985: 69-72; CARTLEDGe, 2009, cap. 7 sobre el juicio de Sócrates.

45 DOVER, 1974: 180-184; Mitchell-RHODES, 1996: 24-26.

46 Cfr. Calmoun, 1913: 10-29; Raubitscheck, 1959: 81-88.

47 Cfr. Gauthier-Jolif, 1970: II, 2, 696-697. 
los regímenes en seis especies, tres rectas y tres desviadas: monarquía, aristocracia y timocracia o república (politeía) y sus correspondientes desviaciones, tiranía, oligarquía y democracia. Aquellos regímenes considerados rectos son los que tienen en vista el interés no de quien gobierna para su propio beneficio sino de los gobernados, por lo que el peor de todos es la tiranía cuyo único beneficiario es el propio tirano. De todos los regímenes los que menos distancia tienen entre sí son la república y la democracia, razón por la cual esta última «es la menos perversa de las constituciones desviadas» (EN, VIII, 12, 1160b, 1-21).

En Política, III, 7 y 8 , ARISTÓTELES retoma esta clasificación general de los regímenes políticos, separándolos de acuerdo con dos criterios: la finalidad (como en EN, VIII, 12) y el número. La clasificación conserva los tres regímenes rectos, monarquía, aristocracia y república (politeía), y los tres desviados: tiranía, oligarquía y democracia. La división entre estas dos últimas es ahora precisada: no se trata solamente del régimen político en el que domina en la primera, una minoría, y en la otra, una mayoría, sino que la verdadera diferencia entre ambas reside en la posesión de riquezas. En efecto, mientras que los ricos, que gobiernan en beneficio propio en una oligarquía, suelen ser pocos, los pobres, en cambio, que ostentan el poder en la democracia basándose exclusivamente en la libertad, muchos (III, 8, 1280a, 1-6). Desde aquí en adelante ARISTÓTELES utilizará un significado descriptivo del término «democracia», aplicado al régimen político sobre la base de la condición social y económica de sus principales sustentadores. Se trata, en realidad, del uso originalmente polémico o peyorativo del término, atestiguado por el panfleto del Pseudo-Jenofonte que ya hemos señalado (vid. \$1). ARISTÓTELES adopta este significado a través del uso platónico, especialmente en el Político 300e ss., pero introduce ciertos matices en torno a los principios de la democracia y separa distintas especies de ella de acuerdo a la forma de ocupar los cargos y de ejercer el gobierno de modo tal que finalmente él convierte al vocablo en un término neutro ${ }^{48}$.

Al comienzo de Política, IV, en la introducción de los tres libros en los que ARISTÓTELES expondrá las conclusiones de su larga investigación sobre los regímenes políticos empíricamente dados, presenta un primer modelo descriptivo o sociológico de democracia, que se basa en la relación causal entre las «partes» o «clases» de la ciudad y el tipo de régimen en el que cada una de ellas predomina:

«... de estas partes [pobres y ricos, campesinos, obreros y comerciantes, etc.] unas veces participan todas en el gobierno y otras un número mayor o menor; es entonces evidente que tiene que haber varios regímenes diferentes entre sí por su forma [...] En efecto, el régimen es una ordenación de las magistraturas, que todos distribuyen según el poder de los que participan de ellas o según la igualdad común a todos ellos [...] Por consiguiente, es forzoso que existan tantos regímenes como ordenaciones según las superioridades y las diferencias de las partes. Sin embargo, parecen existir principalmente dos [...] y los otros [regímenes] se consideran modificaciones de éstos: estas dos formas de gobierno son la democracia y la oligarquía. La aristocracia estaría colocada como una forma de la oligarquía y la llamada república (politeía) como una forma de democracia» (Pol., IV, 3, 1290a, 4-18).

Una diferencia que fue advertida tempranamente por los comentaristas es la siguiente: ARISTÓTELES no sigue aquí el esquema de las constituciones rectas y desvia-

48 MeIer, 1970: 59-67; 1972: 829-833; Dolezal, 1974: 106-122, Mulgan, 1991: 307-322. 
das presentado en Política, III, 7 y ss., sino que presenta otro, limitado en este caso a las dos especies originariamente clasificadas como desviadas, la oligarquía y la democracia ${ }^{49}$. Más adelante al tratar la república ARISTÓTELES hace explícito este cambio de perspectiva:

«Queda por hablar sobre la llamada república [...] Adoptamos este orden aunque la república no sea una desviación, como no lo son tampoco las aristocracias a las que acabamos de referirnos [de acuerdo a lo indicado en III, 7], porque en verdad todas ellas se apartan de la constitución más perfecta [que será tratada en VII, 4 ss.] y, en consecuencia, son contadas entre las desviaciones, que son, en realidad, desviaciones de éstas [que son, a su vez, desviaciones en primer grado de la constitución ideal], como dijimos al comienzo [alusión a III, 7]» (Pol., IV, 8, 1293b, 22-27, trad. Santa Cruz-Crespo, retocada).

Este nuevo esquema distingue una teoría ideal de la constitución política, en la cual las magistraturas están distribuidas de acuerdo con el fin último de la polis, a saber: la obtención de una buena vida, de los demás regímenes existentes. Las constituciones que aúnan la autoridad suprema con la virtud forman un grupo que está a una gran distancia de aquellas otras que no se caracterizan por haber alcanzado esta situación ${ }^{50}$. En esta teoría no-ideal, la distribución de los poderes entre los distintos elementos o partes, el número de los que entran en la distribución y la forma de seleccionarlos, por censo o simplemente por ser libres, y, por último, la forma de ejercer el gobierno, determinan distintas especies de democracia, de modo que se crea una tipología para describir y clasificar las diversas formas históricas que se dieron en Grecia y, en especial, en Atenas ${ }^{51}$.

ARISTÓTELES nos presenta esa clasificación en Política, IV, 4, en la que ordena cinco especies distintas de democracia: (1) una basada en la igualdad de todos los hombres libres, en la que ricos y pobres participan con los mismos derechos de los cuerpos legislativos y de las magistraturas: «la ley de tal democracia determina que los pobres no tengan más poder que los ricos ni que ninguno de ambos grupos sea el soberano, sino que los dos grupos sean semejantes» (Pol., IV, 4, 1291b, 30-35). (2) Una segunda forma de democracia moderada, que establece un umbral bajo de ingresos para la plena participación política en la Asamblea y los tribunales así como los otros cargos electivos. Como vimos más arriba $(\$ 2)$, esta segunda forma de democracia sigue el modelo de la antigua república de los hoplitas, en la que la población habitaba la campaña, ocupada en las labores agrícolas, y se reunía en la ciudad a lo sumo una vez al mes, cuando concurría a la Asamblea ordinaria (Pol., IV, 6, 1292b, 25-34). (3) La tercera especie de democracia está abierta a la participación de todos los hombres libres, es decir, que sean descendientes tanto por parte de padre como de madre de legítimos ciudadanos, y, probablemente, de un matrimonio legítimo, ya que en caso de hijos bastardos no se los incluía directamente en el cuerpo de ciudadanos, a menos que se dieran circunstancias excepcionales (Pol., III, 5, 1278a, 26-34; Ath.Pol., 42, 1) ${ }^{52}$. Si

49 Vid. SidgWICK, 1892: 143-144; NEWMAN, 1892: 290-293; BARKER, 1968: 157-170; MulgAN, 1991: 309 322; SCHÜTRUMPF, 1996: 9, III, 130-140.

50 Cfr. NEWMAN, 1892: 293; SCHÜTRUMPF, 1996: 9, III, 131-133.

51 Cfr. BARKer, 1968: 160 ss. y 188-200; DOLEZAL, 1974: 125 ss.; MiERI, 1987: 77-85; EuCKEN, 1990: 278281; Mulgan, 1991: 307-322; LINTOTT, 1992: 114-128.

52 Vid. la discusión pertinente a la regulación de los ciudadanos legítimos en los siglos V y IV a. C. en Atenas en RHODES, 1985: 496-497. 
bien en este régimen la participación estaba abierta a todos los que cumplieran con las condiciones dadas, de hecho sólo podían participar aquellos que podían disponer de tiempo ocioso para dedicarlo a la política, ya que los que tenían que ganarse el sustento quedaban excluidos de los cargos públicos al no haber dietas para quienes los ocupasen (Pol., IV, 6, 12926 35-38) La condición estricta tanto de esta constitución como de la siguiente para ser tenidas por regímenes políticos bien ordenados es una y la misma: «que gobierne la ley». (4) La siguiente clase de democracia se diferencia de la anterior por el hecho de que se ha debilitado la exigencia de que los ciudadanos proviniesen de padres ciudadanos por ambas partes, de modo que el otorgamiento de la ciudadanía había sido habilitado también para extranjeros e, incluso, hasta para esclavos, como se propuso luego de la caída de los Treinta Tiranos en Atenas en 401/0 a. C. a fin de premiar a los que habían luchado en contra de ellos (Ath. Pol., 40, 2). A pesar de esta laxitud en el otorgamiento de los derechos inherentes a la ciudadanía ${ }^{53}$, ARISTÓTELES enfatiza que aun este tipo de democracia se rige según las leyes generales, de modo de colocar en el último peldaño de la escala la siguiente clase. (5) La quinta y última, en todo sentido, de las especies de democracia «es aquella en la que, siendo todo lo demás igual a la anterior, el poder soberano no lo tiene la ley sino la multitud. Esto ocurre cuando la soberanía es ejercida mediante decretos (psêphismata) pero no mediante leyes» (Pol., IV, 4, 1292a, 4-6). En esta democracia «última o extrema» (teleutaía) todos los ciudadanos, aún los que carecen de recursos, pueden participar de las asambleas y los tribunales populares merced a la introducción de una dieta o salario para facilitar su asistencia, con lo que se logra el efecto contrario: que solamente participen los más pobres y los más ricos deserten de ambos cuerpos (Pol., IV, 6, 1293a, 1-10). Sobre este régimen ARISTÓTELES concentra todas sus críticas: el pueblo llano, seducido por los demagogos, sobrepasa todas las limitaciones impuestas por las leyes y decide en la Asamblea sobre todos los asuntos que son indistintamente puestos a consideración: «el pueblo que se ha degradado de este modo pasa a ser un análogo de la tiranía entre las monarquías. Por eso el carácter de ambos regímenes es el mismo, así como también la sujeción despótica que los dos ejercen sobre los mejores ciudadanos: los decretos de esta forma de democracia son similares a los edictos de una tiranía» (1292a, 17-20). Como conclusión, ARISTÓTELES excluye esta clase de regímenes populares de una «constitución» en sentido estricto, ya que para concedérsele ese carácter un régimen debe cumplir ciertas condiciones ineludibles:

«Es necesario que las leyes determinen mediante normas generales las cuestiones de estado y que los magistrados deban juzgar y resolver sobre los asuntos particulares, para que un régimen político pueda ser considerado una constitución. De modo que, si la democracia es una de las formas constitucionales, evidentemente una manera de gobernar los asuntos públicos de tal modo que todo se ejecute mediante decretos no constituye una democracia en el sentido estricto del término, pues ningún decreto puede establecer normas generales que son propias de las leyes» (1292a, 32-37).

53 El grado de laxitud en la concesión graciosa de estos honores ha sido discutido por los historiadores: vid. RHODES, 1985: 474-477. 


\section{LOS PRINCIPIOS NORMATIVOS DE LA DEMOCRACIA Y DE LA REPÚBLICA EN ARISTÓTELES}

En el libro V de la Ética Nicomáquea ARISTÓTELES analiza la dificultad de fijar el significado de «justicia» en su acepción de «igualdad», ya que «lo justo supone necesariamente un mínimo de cuatro términos, pues aquellos para quienes se da el caso de que algo sea justo, son dos, y las cosas respecto a las que se da, son también dos. Y la igualdad será la misma tanto para ellos como con respecto a estas cosas» (1131a, 15 ss.). A partir de este esquema Aristóteles crea una relación de proporcionalidad entre los individuos $(a: b)$ y las cosas a distribuir $(a: b)$, de modo tal que se mantenga la misma proporcionalidad geométrica, $(a: a=b: b)$. Ahora bien, al tratar de establecer el criterio mediante el que juzgamos los méritos relativos de $a$ y $b$, «no todos juzgan que este mérito resida en lo mismo. Para los demócratas radica en la libertad; para los oligarcas en la riqueza, para otros, en la nobleza de cuna; para los aristócratas, en la excelencia» (1131a, 27-29). Cuando retoma la misma cuestión en la distribución de los cargos en Política III, 9, ARISTÓTELES subraya aquello que provoca los enfrentamientos más radicales e ineludibles entre partidarios de la oligarquía y de la democracia: «unos, si son desiguales en algún aspecto, como por ejemplo en los bienes materiales, creen que son completamente desiguales, mientras que otros, iguales en cierto aspecto, por ejemplo, la libertad, creen serlo en todo» (1280a, 22-25, trad. Santa Cruz-Crespo).

Como vimos en el parágrafo anterior, se encuentran en la Política varios conceptos de «democracia» yuxtapuestos, lo que ha dado lugar a una controversia que aún perdura sobre la concepción definitiva de este régimen, «él menos malo de los regímenes desviados». A fin de esclarecer esta cuestión, es importante evaluar el análisis que ARISTÓTELES brinda de los principios de todo régimen democrático en Política, VI, 2 y 4 y en el que expone claramente el núcleo normativo de éste.

«El fundamento del régimen democrático es la libertad, pues suele decirse que sólo en este régimen se participa de libertad [...] Una característica de la libertad es el de ser gobernado y gobernar por turno, y, en efecto, la justicia democrática consiste en tener todos lo mismo numéricamente y no según los merecimientos, y siendo esto lo justo [a saber: que el criterio mediante el cual se juzgan los méritos de cada uno es únicamente determinar si es un ciudadano libre o no lo es], forzosamente tiene que ser soberana la muchedumbre, y lo que apruebe la mayoría, eso tiene que ser el fin y lo justo. [...] Otra característica es el vivir como se quiere: pues dicen que esto es resultado de la libertad, puesto que lo propio del esclavo es vivir como no quiere. Éste es el segundo rasgo esencial de la democracia, y de aquí vino el de no ser gobernado, si es posible por nadie, y si no, por turno. Esta característica contribuye a la libertad fundada en la igualdad» (Pol., VI, 2, 1317b, 1-17).

Encontramos en este texto nuevamente las notas más destacadas de la concepción tradicional de la democracia, la igualdad de derechos, isonomía, y la libertad, eleuthería, entendida como independencia de toda sujeción externa (esclavitud), alabadas anteriormente por Heródoto, EuRíPIDEs y Tucídides. Por cierto, ARISTÓTEles no pierde de vista la última especie de democracia que él ha condenado en Política, IV, 4, «cuando tienen la supremacía los decretos (tá psêphísmata) y no la ley» (1292a, 5-7). Sin embargo, reafirmando al final del capítulo los rasgos comunes a todas las democracias, indica una gradación en la forma en que cada una de ellas ejercita estos principios. 
«La democracia que más parece merecer ese nombre y el pueblo que es verdaderamente democrático son los que se rigen por el concepto democrático de la justicia admitido por todos, según el cual la justicia consiste en que todos sean iguales en sentido numérico. En efecto, la igualdad consiste en que no gobiernen en mayor medida los pobres que los ricos, sino que todos sean soberanos por igual de acuerdo al número, pues de esta manera podría juzgarse que efectivamente se dan en el régimen la igualdad y la libertad» (Pol., VI, $2,1318 a, 3-10)$.

ARISTÓTELES repite aquí la misma fórmula con la que presentó a la primera especie de democracia en Política, IV, 4, que debemos tomar como la definición normativa modélica del régimen, a la que las distintas especies se aproximan o de la que se distancian. A partir de esta fórmula se esclarece cómo se articulan el significado descriptivo y el normativo en el concepto aristotélico de «democracia». Como señalé más arriba, en su clasificación él adopta el concepto descriptivo y ordena al régimen designado por ese término entre las constituciones desviadas junto a la oligarquía, de modo que ambas se convierten en los dos polos antitéticos entre los cuales quedarán situados los otros dos regímenes, aristocracia y república ${ }^{54}$. Ahora bien, al desarrollar el concepto normativo que establece los criterios que debe satisfacer un régimen para ser considerado democrático, ARISTÓTELES expone simultáneamente las instituciones que son necesarias para satisfacer las exigencias centrales de igualdad, de soberanía y de justicia distributiva. Estas mismas instituciones serán, con matices, también las más apropiadas para la república (politeía). En efecto, la forma moderada de democracia, la democracia agraria (Pol., VI, 4, 1318b, 6 ss.), parcialmente representativa, que combinaba igualdad con elección, y la forma mixta, entre oligárquica y democrática, que constituía la república, se diferencian tan sutilmente entre sí que constituyen en lo esencial uno y el mismo régimen, el de la constitución mixta, que se convertirá de ahora en más en un modelo de un régimen templado que combina las virtudes de uno y otro ${ }^{55}$.

A partir de todos los elementos que se han reunido hasta este punto, es posible hacer una reconstrucción consistente de la concepción aristotélica de la democracia, que será, sin embargo, tan controvertida como todas las que se han intentado anteriormente. En primer lugar es imprescindible tener en mente un aspecto de la ciudad ideal que la hace cualitativamente distinta de todos los otros regímenes: es aquella en la que se dan las condiciones para que los hombres que reúnen virtud y una moderada disponibilidad de los recursos necesarios para la vida puedan gobernarse mediante las mejores leyes, que no apuntan a los intereses particulares sino al interés de la comunidad en vista de una vida feliz (Pol., VII, 3, 1325a, 16-1325b, 32). Por ello, se trata de una forma de aristocracia que está fuera del alcance de una ciudad normal, ya sea porque ésta es demasiado grande, como Atenas, ya sea porque no está suficientemente dotada de recursos, tanto naturales como humanos, o sea, por último, porque los ciudadanos que ofrecen las mejores posibilidades de ser aquellos de una ciudad ideal, como los campesinos que cultivan su propia tierra, precisamente porque deben atender a su trabajo para suplir a sus necesidades y las de su familia, no están disponibles para dedicarse a una vida política sino que tienen que atender sus propios intereses (Pol., IV, 11, 1295a, 25-40; VI, 4, 1318b, 6-20).

54 Kahn, 1990: 380-383; Mulgan, 1991: 311-312, LintotT, 1992: 120-121, SCHÜTRumPF, 1996: 9, III, 331-345.

${ }_{55}$ Cfr. WeIl, 1960: 359-362; AALDERS, 1965: 207-217; DoleZAL, 1974: 178-181. 
$\mathrm{Al}$ concebir el mejor régimen posible dentro de los que están al alcance de una determinada ciudad, es imprescindible además tener presente que, como se ha expuesto más arriba, es imposible llegar a un acuerdo entre las distintas clases que componen la ciudad sobre cuál es el criterio para juzgar si una determinada distribución de los poderes es «justa», ya que cada una se atendrá a su propio juicio, que tratándose de aquello que más afecta a los intereses de cada uno, fácilmente se deja inclinar hacia lo más conveniente para uno mismo (Pol., III, 9, 1280a, 7-25). Dado que los dos contendientes extremos, los más ricos y los más pobres, tienden a ejercer un poder despótico, los primeros por estar acostumbrados a mandar sin resistencias a esclavos y sirvientes, y los segundos, porque, cuando se adueñan de las cuerpos legislativos soberanos, como la Asamblea o los tribunales populares, se comportan del mismo modo, gobernando sin límites mediante decretos que imponen confiscaciones, juicios, condenas y exilios, es necesario crear una democracia de las capas medias que a su vez mezcle las instituciones, de modo que puedan moderarse los conflictos más agudos y gobernar mediante normas generales que sean las mismas para todos y, por eso mismo, previsibles (Pol., IV, 11, 1295b, 1-34).

Desde el punto de vista moral los seres humanos pueden ser divididos en cuatro géneros de acuerdo a su índole: virtuosos, continentes, incontinentes y depravados, de acuerdo con una concepción de psicología moral que distingue a ARISTÓTELES de la tradición socrático-platónica, para la cual solamente había dos clases de personas: los prudentes, que tenían conocimiento del bien, y los ignaros, que carecían de ese conocimiento y, por consiguiente, erraban (EN, VII, 8, 1150a, 10-1150b, 29) ${ }^{56}$. En la psicología moral aristotélica, en cambio, entre los que actúan por imperio de la virtud que los hace elegir el fin que la razón práctica (phrónêsis) les presenta como moralmente bueno y al que la voluntad asiente como digno de ser deseado ${ }^{57}$, y los que persiguen el placer por cualquier medio, a pesar de ser conscientes de que ese fin es contrario a la virtud, como es propio del depravado, existe un campo intermedio en el que se ubica la gran mayoría de los seres humanos. Éstos tienen un conocimiento moral del bien adecuado $\mathrm{y}$, normalmente, son continentes pues dominan sus impulsos contrarios y eligen actuar de acuerdo con lo que prescribe la virtud. Ocasional o habitualmente, sin embargo, pueden también dejarse vencer por el deseo y actuar incontinentemente. Con estos individuos como ejemplares típicos de su ciudadanía debe contar el legislador constituyente cuando diseña el régimen político adecuado para ella.

Cuando ARISTÓTELES expone las propiedades sobresalientes de la que constituye el ejemplo más claro de la mejor democracia, la del pueblo campesino-agrario, (supuestamente idealizada como la «constitución ancestral», e históricamente ligada a la república de los hoplitas), esboza un modelo de constitución en la que se mezclan, por un lado, los rasgos democráticos, - por ejemplo, el hecho de que el pueblo siga siendo soberano y participe de la Asamblea y de los tribunales populares-, y, por otro, aquellos otros rasgos claramente oligárquicos o aristocráticos — como, por ejemplo el hecho de que los cargos de poder sean electivos y que los candidatos sean escogidos mediante una elección por procedimientos basados en la clase censataria o en la formación y capaci-

56 Vid. sobre esta clasificación el excelente comentario de GAUTHIER-JOLIF, 1970: II, 2, 579-583.

57 Para el análisis de este modo de comprender la deliberación y elección en el acto moral según ARISTÓTELES, remito a la discusión en GUARIGLIA, 1997b: 191-217. 
dad para el oficio- (Pol., VI, 4, 1318b, 11-1319a, 3). El razonamiento mediante el cual ARISTÓTELES sostiene la bondad de este orden político, pone de manifiesto el juicio más maduro del filósofo sobre los asuntos humanos y al hacerlo, expresa por primera vez un principio que pasará a ser axiomático para toda constitución política futura.

Pol., VI, 4, 1318b, 35-1319a, 3. «También para estos ciudadanos más distinguidos esta constitución será satisfactoria, ya que no serán gobernados por los otros, que son en todo inferiores, y ellos mismos gobernarán por su parte de una manera equitativa y justa, puesto que son los otros los que tienen el control soberano de las rendiciones de cuentas. En efecto, el hecho de estar sujeto a la supervisión de otro y de no poder hacer lo que a uno le parezca es muy conveniente. Pues la posibilidad de hacer lo que cada uno desea no permite vigilar y sojuzgar los viles impulsos que están en el interior de cada ser bumano. De este modo se logra necesariamente un orden político que es el más beneficioso para las constituciones, a saber: que gobiernen aquellos que por su capacidad y mérito son los menos dispuestos a cometer errores [de los cuales deberán rendir cuentas], mientras que la muchedumbre [democrática] no es en ningún caso tratada como una clase inferior».

El pasaje tiene un evidente paralelismo con otro famoso texto de I. KANT, en el que éste resueltamente afirma que «el problema del establecimiento del estado es resoluble, por más difícil que pueda parecer su solución, incluso para un pueblo de demonios, siempre que éstos posean entendimiento» (ZeF, VIII, 366 Ak; VI, 224 W). En ambos casos de lo que se trata, mediante un sistema de supervisiones mutuas y coacciones cruzadas, es de obtener una conducta pública de todos los implicados que obedezca a una regla común. Cuando ésta es anulada unilateralmente por alguna de las partes involucradas, estamos en presencia de un sistema basado exclusivamente en el abuso despótico del poder, sea en el caso de una democracia, de una oligarquía o, en el peor de todos, de una tiranía. Por esta razón la diferencia específica que separa tanto a las especies de la democracia como de la oligarquía es el respeto por la ley. Sin éste, en efecto, deja de existir un régimen constitucional como tal, de un modo semejante a como en los regímenes populistas de uno y otro signo, del siglo XIX hasta el presente, el arbitrio del caudillo o conductor se coloca en todos los casos por encima de la constitución.

\section{SEDICIÓN Y CAMBIO VIOLENTO DE RÉGIMEN}

En Ética Nicomáquea, IX, 6 ARISTÓTELES analiza a lo largo de todo el capítulo el significado del término «consenso» (bomónoia), señalando un rasgo específico que está analíticamente contenido en el sentido de aquél: «no decimos que los que piensan lo mismo por ejemplo sobre los fenómenos celestes [logran un consenso]». En efecto, el término «consenso» remite implícitamente a las decisiones que se relacionan con las acciones conjuntas de muchos: «se dice que una ciudad «tiene un consenso» cuando sus ciudadanos piensan lo mismo sobre lo que los beneficia, se proponen los mismos fines y llevan a cabo las resoluciones tomadas en conjunto» (EN, IX, 6, 1167a, 25-28). Por el contrario, señala ARISTÓTELES, «cuando cada una de las partes pretende para sí todo lo que está en juego, entonces se produce un enfrentamiento sedicioso (stasiázein), como el de [Etéocles contra Polinices en] Las fenicias [de EuRíPIDEs]» (1167a, 
32-34). En conclusión, añade, «el consenso es manifiestamente, por su sentido y por el uso lingüístico del término, una forma política de la amistad» (1167b, 2-3).

En la Política, V, ARISTÓTELEs examina el origen y las causas de la fractura irremediable del consenso que conduce a la sedición (stásis) y, en el caso extremo, al cambio de régimen. La cuestión clave en torno a la cual se crea primero el desacuerdo y de inmediato la ruptura que conduce a la revuelta, es la ya conocida diferencia en la interpretación de la justicia. Para los partidarios de la democracia, por ser todos igualmente libres, los ciudadanos deben ser también iguales en todo lo demás. Para los de la oligarquía, por ser desiguales en el patrimonio, ellos deben ser considerados absolutamente desiguales también en todos los demás aspectos (Pol., V, 1, 1301a, 25-35). Dado que, como se ha señalado, en todos los estados existen los ricos y los pobres y dado que son estas dos clases las que monopolizan las dos formas de gobierno opuestas entre sí, oligarquía y democracia, son estos dos los regímenes más expandidos a través de las distintas ciudades-estados. De un modo consecuente ARISTÓTELES señala que los cambios que se buscan, pueden ser de dos maneras:

«... unas veces, en contra del régimen político, para cambiar del que está establecido a otro, por ejemplo, de una democracia a una oligarquía, o de una oligarquía a una democracia, o bien de éstas a una república y una aristocracia, o de éstas a aquéllas. Otras veces, no en contra del régimen establecido, sino que prefieren el mismo orden de cosas, aunque desean manejarlo ellos mismos...» (Pol., V, 1, 1301b, 6-13; trad. Santa Cruz-Crespo, con leves cambios).

No es el propósito de esta sección dedicarse a examinar en detalle el libro $\mathrm{V}$ de la Política, que, como bien se ha señalado, abunda en un preciosismo de detalles y ejemplos a expensas de la claridad en la exposición general de su argumento ${ }^{58}$. El análisis que sigue se limitará a presentar las condiciones necesarias que ARISTÓTELES aísla de la infinidad de fenómenos que anteceden a una sedición, en especial para las democracias y las oligarquías y los dos regímenes ligados a cada una de ellas, república y aristocracia. Estas condiciones necesarias (aunque no siempre suficientes) son de tres clases: a) el estado de ánimo de los protagonistas, b) los asuntos que están en disputa y c) el punto de partida de los disturbios y de las sediciones.

a) Aquello que influye de modo determinante en el estado de ánimo de los directamente involucrados es la percepción de desigualdad (o de igualdad) en relación con otros a los que no se considera superiores (o a los que se considera inferiores en algo). «Los que aspiran a la igualdad se lanzan a la sedición si consideran que, aunque son iguales a los que tienen más, tienen menos que ellos; y los que aspiran a la desigualdad y la superioridad, si suponen que, aunque son desiguales, no tienen más sino igual o menos —siendo indistinto que al aspirar a esas metas puedan hacerlo justa o injustamente-》 $(1302 b, 24-29)$.

b) Hay dos asuntos que son siempre objeto de las más violentas disputas: la ganancia y el honor que se pueden obtener (lícita e ilícitamente), en especial mediante los recursos que brindan los asuntos de estado. En ambos casos, también valen como condiciones sus respectivos contrarios: evitar las pérdidas e impedir el deshonor.

58 Vid. especialmente WHEELER, 1951: 148-149; además del trabajo inicial de éste véanse para la discusión más específica con respecto a la interpretación de este difícil libro, WEIL, 1960: 339-365; POLANSKY, 1991: 321 345; SCHÜTRUMPF, 1996: 164-185, y MiLLER, 1997: 293-308. 
c) Los motivos que son puntos de partida para disturbios y sediciones son, además de los dos ya indicados, ganancia y honor, otros, tales como soberbia, miedo, afán de superioridad, desprecio, incremento desmesurado de una parte del estado, etcétera.

Si bien éstas son en general las condiciones que deben estar presentes, directa o indirectamente, los motivos que se indican pueden ser fútiles para que un disturbio degenere en una sedición, pero la sedición no surge por esas nimiedades sino a propósito de ellas. El trasfondo de cada sedición es un enfrentamiento por el poder, que unas veces puede solucionarse mediante los recursos provistos por las leyes, como es el caso de la imposición del ostracismo a aquellos que han descollado por una acumulación excesiva de poder, y otras conduce directamente al cambio de régimen mediante la sedición (V, 3, 1320b, 10-20). De ahí que, en términos generales, y desde el punto de vista de la estabilidad intrínseca de cada régimen, «la democracia es más segura y estable que la oligarquía», pues esta última está constantemente expuesta a dos tipos de sedición: «la de los oligarcas entre sí y la de éstos contra el pueblo», mientras que «en democracia no hay ejemplos dignos de mención de una sedición del pueblo contra sí mismo» (V, 1, 1302a, 8-15).

Desde una perspectiva que sólo considera la estabilidad intrínseca de los regímenes, Aristóteles provee una máxima general que reza así:

«... el elemento que ya hemos repetidamente señalado y el más importante es el siguiente: se debe velar para que la parte de la población que apoya la constitución sea mayor y más fuerte que la que no la quiere. Además de todo esto no debe olvidarse algo que las constituciones desviadas ahora olvidan: la existencia de la clase media [y de la medida], pues muchas de las decisiones que supuestamente son democráticas destruyen las democracias, y muchas de las que supuestamente son oligárquicas, destruyen las oligarquías» (Pol., V, 9, $1309 b, 15-21)$.

La superioridad de la constitución mixta se basa precisamente en su capacidad para sostenerse amortiguando sus conflictos internos, razón por la cual «es la más estable de todas las constituciones» (Pol., V, 1, 1302b, 15). A la inversa, los regímenes que no aciertan al atemperar sus conflictos, inclinándose demasiado hacia alguno de los dos extremos, al de la democracia radical o al de la dinastía oligárquica, están destinados al fracaso y al cambio violento (Pol., V, 7, 1307a, 5-25).

\section{CONCLUSIÓN: ¿ «DEMOCRACIA»: GOBIERNO DE LAS LEYES O GOBIERNO DE LA MASA?}

Desde la Antigüedad existe un extendido prejuicio sobre el pensamiento político de ARISTÓTELES como un adversario de la democracia, junto a sus dos antecesores más influyentes, Platón e Isócrates ${ }^{59}$. Pese a ello, es claro que aquél, a diferencia de éstos, se sumió en un examen exhaustivo y detallado de los diferentes regímenes e, inclusive, de las distintas especies de cada uno de ellos, sopesando ventajas y desventajas en vista de la propia estabilidad intrínseca y de su eficacia gubernativa con independencia del propio juicio normativo sobre el mismo. Una conclusión general que ARISTÓTELES

59 Vid., por ejemplo, LARSEN, 1954: 1-14. 
extrae de este examen proviene de la propia estructura social de las ciudades griegas, en las que las contingencias de la formación y la conquista de los estados había sedimentado una estructura de capas desiguales en riqueza y poder. El surgimiento primero de los hoplitas de la clase media y, más tarde, en las ciudades marítimas como Atenas luego de las Guerras Médicas, de una flota naval poderosa tripulada abrumadoramente por la clase de desposeídos, los thêtes, desniveló estas ventajas originales, pero al precio de un permanente conflicto interno que amenazaba con desequilibrar la constitución política, inclinándola hacia los extremos: la oligarquía tiránica (dynasteía) o la democracia extrema de la masa desposeída. ¿Cómo evitar en lo posible que este conflicto degenere en sedición y en cambio cruento de régimen?

ARISTÓTELES analiza por primera vez las tres partes constitutivas de un régimen político: en primer lugar, la institución que delibera y tiene a su cargo la sanción de las leyes, la declaración de la guerra y de la paz, de las alianzas y la denuncia de éstas, etc.; en segundo lugar, los cargos ejecutivos de gobierno, su forma de nombramiento y de control, etc.; por último, los tribunales y, de modo muy importante, su conformación, si por elección o por sorteo de entre los miembros del pueblo llano (Pol., IV, 14, 1297b, 35-1298a, 9). Cuando las tres instituciones caen en manos del mismo partido, inevitablemente se crea un régimen despótico que se rige unilateralmente mediante decretos. Los antiguos tiranos habían surgido mediante el dominio del ejército y del poder militar (el carisma de la espada, según M. WEBER), los nuevos, los demagogos, carentes de aptitudes militares, mediante el dominio de la Asamblea a través de su oratoria y de su maestría en el arte de la retórica (el carisma del discurso, según M. WeBER) (Pol., V, 5, 1305a, 7-15). En ambos casos, el resultado es el mismo: la desaparición del régimen constitucional.

$\mathrm{Al}$ analizar la cuarta especie de democracia (que es idéntica a la quinta en la clasificación general expuesta en $\mathbb{S} 3$ ), ARISTÓTELES pone al descubierto la que se puede bautizar como «la falacia de la democracia directa», cuando señala que «la masa de artesanos, vendedores ambulantes de la plaza y jornaleros [...], toda esta gente, por el hecho de estar rondando en los alrededores de la plaza y en el [centro] de la ciudad, rápidamente se reúnen en la Asamblea, mientras que los campesinos, por el hecho de estar dispersos por todo el campo, ni participan con alguna frecuencia de las reuniones de ésta ni tampoco sienten la necesidad de tomar parte de esos encuentros» (Pol., VI, 4, 27-32). Así puede entenderse que se considerara un quórum aceptablemente representativo de toda la ciudadanía el formado por escasamente la sexta parte de todos los ciudadanos habilitados para formar parte de ella -6.000 de un total aproximado de 36.000 ciudadanos-, en el siglo IV y menos de la séptima parte en el siglo v. No resulta tan errado, entonces, el juicio condenatorio de Aristóteles, cuando compara esa especie de democracia con la tiranía. Se trata, por cierto, de una democracia muy limitada en su concepción de la representación de la voluntad de todos, ya que se maneja por decretos votados por una cambiante minoría que, en el mejor de los casos, representa escasamente el 13 por 100 de solamente la población masculina, es decir, sin contar mujeres, extranjeros residentes y esclavos. La «democracia», entonces, arguye ARISTÓTELES, no puede ser confundida con esta especie «última», sino que hay que identificarla con su modelo normativo más puro, aquel en el que rigen la igualdad y la libertad para todos por igual, en el que se gobierna por turno y en el que rigen la constitución y las leyes, de modo que todos los ciudadanos, ricos, medios y pobres, puedan 
tener un horizonte político previsible y estable. Este régimen, en cierto modo utópico o ideal dentro de los asequibles en las condiciones de la realidad empírica, es la que indistintamente puede llamarse una «democracia», una «oligarquía» o una «república», y que se logra mediante la mezcla de estos regímenes, a fin de obtener la constitución más estable y equilibrada:

«Éste es el modo de llevar a cabo la mezcla [de oligarquía y democracia para crear una república (politeía)]. La definición de una buena mezcla entre democracia y oligarquía está dada por lo siguiente: cuando es posible llamar a una misma constitución «democracia» y «oligarquía», entonces se ha tenido éxito al realizar la mezcla de ambas. Esto ocurre también al lograr un término medio entre dos extremos, pues ambos se presentan en él, lo cual es el caso en la constitución de los Lacedemonios» (Pol., IV, 9, 1294b, 13-19).

Se suele trivializar la propuesta aristotélica, considerándola una interferencia de su teoría ética del término medio como el fin que debe ser elegido en toda acción virtuosa $^{60}$. Que ésta no pasa de ser una suposición tan desviada como infundada lo demuestra el hecho de que la consecuencia que se debiera seguir de una elección de la clase media por ser tal es que esta clase es en sí la más virtuosa, cosa que ARISTÓtELES está lejos de sostener en la Política. Sus razones para una combinación de todas las clases en una constitución mixta están guiadas exclusivamente por el fin de obtener un régimen en el que todos los componentes de la ciudadanía estén representados y tengan un interés propio de cada uno de ellos por mantener ese régimen y preservarlo de toda posible sedición. De hecho, no puede decirse que él sea demasiado optimista en que esa meta pueda lograrse en las condiciones propias de la ciudad estado-antigua. Como bien señala, basta un crecimiento desparejo o desmedido de la población - $\mathrm{y}$ claramente se refiere a la clase más desprovista de recursos- para dar al traste con el equilibrio mejor logrado. Sin duda, a quien de entrada ha señalado que la gran oposición en toda ciudad es la de los ricos y de los pobres, no se le escapa que el gran problema a resolver en la ciudad-estado antigua era el de la distribución de recursos que pudieran permitir una vida un poco por encima del nivel de indigencia para toda la población. En las condiciones de un gran estado, como Atenas, en el siglo v, la solución temporaria fue la creación de un imperio marítimo que expoliaba a sus aliados con el fin de sostener su propio proletariado, que además era el que proveía de marineros sus naves de guerra. Las grandes democracias de la Antigüedad, ya sean restringidas a guerreros hoplitas con medianos recursos, como Esparta, o ya sean populares, como Atenas, necesariamente vivían de alguna forma de explotación de otras poblaciones y de la sujeción mediante la guerra. En esas condiciones, en las que la economía era básicamente agraria y tradicional, sin grandes avances y sin interés por la innovación tecnológica y el aumento de la productividad, la resolución del conflicto por la distribución más o menos equitativa o medianamente satisfactoria de los recursos era, a la larga, imposible ${ }^{61}$. Una vez estudiados los tres libros centrales de la Política y su disección de los regímenes políticos, especialmente los dos más expandidos, las distintas especies de oligarquía y de democracia, no es posible sostener que la conclusión que se extrae de ellos sea unilateral o que dé lugar a un optimismo carente de perspicacia. Sin duda, ARISTÓTELES no deja de señalar las que a su juicio son las posibles alternativas,

60 Por ejemplo Finley, 2002: 10.

${ }^{61}$ Cfr. FinLEY, 1965: 29-45, para la ausencia de innovación tecnológica, y 2002: 1-22 para la permanencia ineludible del conflicto de clases en la Antigüedad clásica. 
bajo ciertas condiciones. Avanzando mediante contrastes, frente a los regímenes que no ofrecen vías de salida, salvo la sedición cruenta y el cambio radical, presenta aquellos que, mediante el control recíproco de los poderes, logran un gobierno sostenido en el consenso, es decir, en la amistad política. Ésta será la herencia que, bajo el título de republicanismo clásico, dejará la filosofía política aristotélica a sus sucesores helenísticos, romanos y a través de ellos, al humanismo renacentista ${ }^{62}$. En este trabajo hemos procurado resaltar que el modelo de una república posible elaborado por ARISTÓTELES no surge, como en el caso de su maestro, de una teoría metafísica abstracta, sino de un profundo examen de la historia de los regímenes políticos, en especial de la oligarquía y la democracia, de su análisis de las partes que los componen y, por último, de la combinación de los elementos normativos implícitos en cada uno de ellos y de la ingeniería institucional necesaria para llevarlos a la práctica. Quizás haya sido la creación y aplicación de este extraordinario método de indagación filosófica de los fenómenos políticos lo más valedero y vigente de su legado.

\section{BIBLIOGRAFÍA}

AALDERS, G. J. D., 1965: «Die Mischverfassung und ihre historische Dokumentation in den Politica des Aristoteles», en Fondation Hardt, 1965, 199-244.

ANDREWES, A., 1938: «Eunomia», Classical Quaterly, 32, 89-102.

— 1977, «Kleisthenes' Reform Bill», Classical Quaterly, 27, 241-248.

ARISTÓTEles: EN: Ethica Nicomachea, editada por I. BYwATER, Oxford, Clarendon Press, 1894.

- EE: Ethica Eudemia, editada por R. R. Walzer y J. M. MingaY, Oxford, Clarendon Press, 1991.

- Rhet: Rhetorica, editada por W. D. Ross, Oxford, Clarendon Press 1959.

- De arte poet.: De arte poetica, editada por R. KASSEL, Oxford, Clarendon Press, 1965.

- Pol: Politica, editada por W. D. Ross, Oxford, Clarendon Press, 1957.

- Ath. Pol., Athenaion Politeia, editada por H. RackHam, London-Cambridge, Mass., Loeb Classical Library, 1935.

- Texte établi et traduit par G. Mathieu et B. Haussoullier, Paris, Les Belles Lettres, 1972.

- Texto editado por O. GigON, Frag. 474, 581a-616b.

- Frag., Librorum deperditorum fragmenta, editada por O. GIGON, Berlin, W. de Gruyter, 1987.

Traducciones y comentarios:

- L'Éthique a Nicomaque, introd., trad. y comentario de R. A. GAUTHIER y J. Y. Jolif, 1970, II tomos en tres partes, Louvain-Paris, P. Universitaires-Beatrice-Nauwelaerts.

- The Politics of Aristotle, edición comentada en 4 tomos de W. L. Newman, Oxford, 1887.

- The Politics of Aristotle, traducción, introducción y notas de E. BARKER, Oxford, Clarendon Press, 1968.

- Política, edición y traduc. M. Araujo y J. Marías, Madrid, Instituto de Estudios Políticos, 1970.

- Politik, traducción y comentario de E. SCHÜTRUMPF, Aristoteles Werke in deutscher Übersetzung, t. 9, en cuatro partes, Berlin, Akademie Verlag, 1991-1996.

${ }^{62}$ Cfr. Nelson, 2004: 1-5. 
- Política, Introducción, traducción y notas de M. Isabel SANTA CruZ y M. Inés CresPo, Buenos Aires, Losada, 2005.

- Staat der Athener, traducción al alemán y comentario de M. CHAMBERS, Aristoteles Werke in deutscher Übersetzung, t. 10, Berlin, Akademie Verlag, 1990.

Austin M., y Vidal-Naquet, P., 1972: Économies et sociétés en Grèce ancienne, Paris, A. Colin.

BARKer E., 1959: The Political Thought of Plato and Aristotle, New York, Dover.

- 1968: The Politics of Aristotle, Oxford, Clarendon Press.

Bengston, H., 1977: Griechische Geschichte, 5. a ed., München, C. H. Beck.

BIEN, G., 1973: Die Grundlegung der politischen Philosophie bei Aristoteles, Freiburg-München, Alber.

Boвbio, N., 1985: El futuro de la democracia, trad. esp., Barcelona, Plaza \& Janés, 1985.

Bowersock, G. W., 1967: «Pseudo-Xenophon», Harvard Studies in Classical Philology, 71, 33-55.

Braun, E., 1973: «Die Summierungstheorie des Aristoteles», en Steinmetz, 1973, 378-395.

Busolt, G., 1963: Griechische Staatskunde, t. I, München, C. H. Beck, 1963 (Handbuch der Altertumswissenschaften, t. IV 1).

Calhoun, G. M., 1913: Athenian Clubs in Politics and Litigation, Reprint: New York, 1970 (acces. en: http://books.google.com.ar/books?id=HwrKqO06K1oC\&pg=PP6\&lpg=PP1\& ots $=7$ KTA1jULs $8 \& d q=$ Calhoun + por $1002 \mathrm{~B}+$ Athenian + Clubs + in + Politics + and + Litigatio

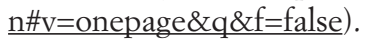

Cartledge, P., 1977: «Hoplites and Heroes: Sparta's Contribution to the Technique of Ancient Warfare», Journal of Hellenic Studies, 97, 11-27.

- 2009: Ancient Greek Political Thought in Practice, Cambridge, U.P.

Chambers, M., 1990: Aristoteles Werke, t. 10: Staat der Athener, Introducción y comentario, 73-458.

DAHL, R. A., 1989: Democracy and its Critics, New Haven-Londres, Yale U.P.

Davies, J. K., 1971: Athenian Propertied Families 600-300 B.C., Oxford, Clarendon Press.

DAY, J., y ChAmbers, M., 1967: Aristotle's History of Athenian Democracy, Amsterdam, Hakkert.

De Sanctis, G., 1912: Athis: Storia della Repubblica Ateniense, 2. ${ }^{a}$ ed., Torino, Fratelli Bocca.

Detienne, M., 1968: «La phalange. Problèmes et controverses», en Vernant, 1968, 119-142.

Diels, H., y Kranz, W. (eds.), 1956: Die Fragmente der Vorsokratiker, 3 tomos, Berlin, Weidmann.

Dolezal, J. P., 1974: Aristoteles und die Demokratie, Frankfurt M., Akademische Verlagsgesell.

Dover, K. J., 1974: Greek Popular Morality in the Time of Plato and Aristotle, Oxford, Blackwell.

DüRING, I., 1966: Aristoteles: Darstellung und Interpretation seines Denkens, Heidelberg, C. Winter.

EDER, K., 1976: Die Entstebung staatlich organisierter Gesellschaft, Francfort, Suhrkamp, 1976.

EDmonds, J. M. (ed.), 1961: Elegy and Iambus, II tomos, Londres-Cambridge, Mass., W. Heinemann-Harvard U.P. (The Loeb Classical Library).

EhrenberG, V., 1950: «Origins of Democracy», Historia, 1, 515-548.

- 1965: Der Staat der Griechen, 2. ed., Zürich-Stuttgart, Artemis, 1965.

Esquilo: Supplices, edic. de G. Murray, 1955, Oxford, Clarendon Press (Oxford Classical Texts).

Euben, J. P., 1993: «Democracy Ancient and Modern», Political Science and Politics, 26, 478-481. 
EUCKEN, CH., 1990: «Der aristotelische Demokratiebegriff und sein historisches Unfeld», en G. PATzig, 1990, 278-293.

EuRíPIDEs: Supplices, edic. de G. Murray, 1962, Oxford, Clarendon Press (Oxford Classical Texts, t. 2).

Evanston, S., 1988: «Aristotle on the Foundations of the State», Political Studies, 36, 89-101.

FInLEY, M. I., 1953: «Land, Debt and the Man of Property in Classical Athens», Polit. Science Quat. 68, 249-268.

- 1964a: «Between Slavery and Freedom», Comparative Stud. Soc. and Hist. 6,233-249.

- 1964b (comp.): Slavery in Classical Antiquity: Views and Controversies, 3. ${ }^{\mathrm{a}}$ ed., Barnes \& Noble, New York, 1968.

- 1965: «Technical Innovation and Economic Progress in the Ancient World», Economic History Review, $2^{\text {nd }}$ Series 18, 29-45.

- 1968: «Sparta», en Vernant, 1968, 143-160.

- 1973a: The Ancient Economy, Londres, Chatto \& Windus.

- 1973b (comp.): Problèmes de la terre en Grèce ancienne, Paris-La Haya, Mouton \& Co.

- 1974a (comp.): Studies in Ancient Society, Londres y Boston, Routledge and Kegan Paul.

— 1974b: «Athenian Demagogues», en FInLEy (comp.), 1974a, 1-25.

- 1977: Uso y abuso de la bistoria, t.e., Barcelona, Crítica.

- 1982: Esclavitud antigua e ideología moderna, t.e., Barcelona, Crítica.

- 1985: Democracy Ancient and Modern, revised edition, New Brunswick, NJ, pb ed. 1996.

- 2002: Politics in the Ancient World, Cambridge, U.P.

Flashar, H., 1971: «Ethik und Politik in der Philosophie des Aristoteles», Gymnasium, 78,b, 278-293.

- 1983: «Aristoteles», Grundriss der Geschichte der Philosophie, Bd.3, 175-457, Basel-Stuttgart, Schwabe.

Fondation HaRDT, 1965: La «Politique» d'Aristote, Vandoeuvres-Genève (Entretiens Hardt s. l'Antiquité Classique, t. XI).

GAUTHIER, R. A., y JOLIF, J. I., 1970: L’Ethique à Nicomaque: Introduction, traduction et commentaire, 3 vols., 2. ${ }^{a}$ ed., Lovaina-Paris, Public. Universitaires.

GERNET L., 1964: «Sur la notion du jugement en droit grec», en Droit et societé dans la Grèce ancienne, Paris, 61-81.

GlotZ, G., 1920: Le travail dans la Grèce ancienne, Paris, F. Alcan, 1920.

- 1948: Histoire grecque, con la colaboración de R. CoHEN, 2 tomos, Paris, Presses Universitaires de France.

- 1953: La cité grecque, Paris, A. Michel.

Guariglia, O., 1966: «Anaximandro de Mileto», Anales de Filología Clásica, 9, 23-155.

- 1979a: «Dominación y legitimación en la teoría política de Aristóteles», Rev. Latinoam. Filos., 5, 15-42.

- 1979b: «La Política de Aristóteles en una nueva perspectiva», Rev. Lat. Filos., 5/1, 79-89.

- 1990: «Los fundamentos discursivos de la democracia y los conflictos de intereses», Diánoia, 36, 83-95.

- 1991: «Problemas conceptuales de la democracia», en D. SobreVILla, ed., El derecho, la política y la ética, México, Siglo Veintiuno, 83-94.

- 1996: Moralidad (Ética universalista y sujeto moral), Buenos Aires, Fondo de Cultura Económica (Biblioteca de Filosofía), 340 pp.

- 1997a: «La eudaimonía en Aristóteles: un re-examen», Méthexis, 10, 83-104. 
- 1997b: La Ética en Aristóteles o la moral de la virtud. Buenos Aires, Eudeba, 394 pp.

- 2002a: Una ética para el siglo XXI. (Ética y derechos bumanos en un tiempo posmetafísico), Buenos Aires, Fondo de Cultura Económica, 2002 (Colección popular, 611).

— 2002b: «Eudemonismo y virtud en la ética antigua: Aristóteles y los estoicos», Diálogos, 80 (julio), 7-49.

- 2010: En camino de una justicia global, Madrid-Barcelona, Marcial Pons.

Guthrie W. K. C., 1969: A History of Greek Philosophy, 6 tomos, Cambridge, Cambridge U.P. Habermas, J., 1992: Faktizität und Geltung, Francfort, Suhrkamp.

- 1997: Die Einbeziebung des Anderen, Francfort, Suhrkamp.

- 2005: Zwischen Naturalismus und Religion, Francfort, Suhrkamp.

Hammond, N. G. L., 1940: «The Seisachtheia and the Nomothesia of Solon», Journal of Hellenic Studies, 60, 71-83.

- 1961: «Land Tenure in Attica and Solon's Seisachtheia», Journal of Hellenic Studies, 81, 76-98.

Hansen, M. H., 1999: The Athenian Democracy in the Age of Demosthenes, 2. ${ }^{a}$ ed., Norman, U. of Oklahoma Press.

Harris, E. M., 2002: «Did Solon Abolish Debt-bondage?», Classical Quaterly, 52, 415-430.

Harrison A. R. W., 1957: «Aristotle's Nicomachean Ethics, Book V, and the Law Athens», Journal Hellenic Studies, 77, 42-47.

Hasebroek, J., 1928: Staat und Handel im Alten Griechenland, reproducción de 1. a ed. (Tübingen 1928), Hildesheim, Olms, 1966.

- 1931: Griechische Wirtschafts- und Gesellschaftsgeschichte, Tübingen.

Heinimann F., 1965: Nomos und Physis, 2." ed., Darmstadt, Wissenschaftliche Buchgesellschaft.

Held, D., 1987: Models of Democracy, Cambridge, Polity Press.

Heródoto: Historias, edic. y trad. franc. por Ph. Legrand, Paris, Les Belles Lettres, 8 tomos, 1949.

HöFfE, O., 1970: Praktische Philosophie: Das Modell des Aristoteles, München-Salzburg, Pustet.

- 1979: Ethik und Politik, Francfort, Suhrkamp.

JAEGER, W., 1946: Aristóteles: bases para la historia de su desarrollo intelectual, tr. esp., México, Fondo de Cultura Económica.

- 1957: Paideía, tr. esp., México-Buenos Aires, Fondo de Cultura Económica.

Jenofonte: Memorabilia, ed. de E. C. Marchant, Opera Omnia, t. II, Oxford, Clarendon Press, 1921.

Ps.-Jenofonte: Atheniensium Respublicam, ed. de E. C. Marchant, Opera Omnia, t. V, Oxford, Clarendon Press, 1920.

KaHn, Ch., 1990: «The Normative Structure of Aristotle's Politics'», en G. PATZIG, 1990, 369-384.

KAnt, I., y Werke, M. S.: Die Metaphysik der Sitten, Werke IV, 309-634, editadas por W. WEISCHEDEL, 6 t., Darmstadt, Wissenschaftliche Buchgesellschaft, 1966. ZeF: Zum ewigen Frieden, Werke VI, 194-251; Ak. VIII, 325-39.

KeAney, J. J., 1969: Ring Composition in Aristotle's Athenaion Politeia, 90, 406-423.

Keyt, D., y Miller, F. (eds.) 1991: A Companion to Aristotle's Politics, Oxford, Blackwell.

KIRK, G., 1954: Heraclitus: The Cosmic Fragments, Cambridge, University Press.

KLuWE, E., 1976: «Die soziale Zussammensetzung der athenischen Ekklesia und ihr Einfluss auf politische Enscheidungen», Klio, 58, 295-333. 
Knox, R., 1985: «So Mischievous a Beaste? The Athenian Demos and its Treatment of its Politicians», Greece E Rome, 32, 132-161.

Kullmann, W., 1980: «Der Mensch als politisches Lebewesen bei Aristoteles», Hermes, 108, 419-443.

KymLICKA, W., 1988: «Liberalism and Communitarianism», Canadian Journal of Philosophy, 18, 181-203.

LarSEn, J. A. O., 1954: «The Judgement of Antiquity on Democracy», Classical Philology, 49, 1-14.

LEG: Leges, editado por Ed. des Places, 1951, con una introducción de A. DiEs y L. GERnET, 4 t., Paris, Belles Lettres.

LESKY, A., 1963: Geschichte der Griechischen Literatur, Berna y München, Francke.

— 1974: «Die Datierung der "Hiketiden" und der Tragiker Mesatos», en H. Hommel, Wege zu Aischylos, Darmstadt, Wiss. Buchgesell., II, 83-100 [publicado originalmente en Hermes, 82 (1954) 1-13].

LinTotT, A., 1992: «Aristotle and Democracy», Classical Quarterly, 42, 114-128.

LIPSET, S. M., 1963: El hombre político: las bases sociales de la política, tr. esp., Buenos Aires, Eudeba.

Macpherson, C. B., 1973: Democratic Theory, Oxford, Clarendon Press, 1973.

- 1982: La democracia liberal y su época, tr. esp., Madrid, Alianza.

Manin, B., 1987: «On Legitimacy and Political Deliberation», Political Theory, 15, 338-368.

Manville, B., 1980: «Solon's Law of Stasis and Atimia in Archaic Athens», Transactions and Proceedings of the American Philological Association, 110, 213-221.

MARX, K.:, Grundrisse, Grundrisse der Kritik der politischen Ökonomie, reprod. fotomec. de la 1. 'ed. (Moscú 1939 y 1941), Francfort, Europäishe Verlag., s.f.

Mattingly, H., 1997: «The Date and Purpose of the Pseudo-Xenophon Constitution of Athens», Classical Quaterly, 47, 352-357.

MCCarthy, Th., 1978: The Critical Theory of Jürgen Habermas, Cambridge, Mass., The MIT Press, 1979.

MeIER, Ch., 1966: Res Publica Amissa (Eine Studie zu Verfassung und Geschichte der späten Römischen Republik), Wiesbaden, F. Steiner Verlag.

- 1970: Die Entstehung des Begriffs Demokratie, Frankfurt M., Suhrkamp.

- 1972: «Demokratie: Einleitung, Antike Grundlagen», en O. Brunner, W. ConZE, y R. KoSELLECK, Geschichtliche Grundbegriffe, Stuttgart, Klett-Cotta, vol. I, 821-835.

Mitchell, L., y RHodes, P., 1996: «Friends and Enemies in Athenian Politics», Greece E Rome, 43, 11-30.

MierI, M., 1987: «Biología y taxonomía de las constituciones en la Política de Aristóteles», Revista Latinoamericana de Filosofía, 13, 72-85.

MiLl, J. S., 1859: «On Liberty», en Utilitarianism, On Liberty, Essay on Bentham, editados con una Introducción por M. WARNOCK, Glasgow, Collins Fount Paperbacks, 1979.

- 1861: Considerations on Representative Government, Londres, G. Routledge \& Sons; Nueva York, E. P. Dutton \& Co., s.f.

Miller, F. D., Jr., 1997: Nature, Justice and Rights in Aristotle's Politics, Oxford, Clarendon Press.

Mommsen, W., 1974: The Age of Bureaucracy: Perspectives on the Political Sociology of Max Weber, Oxford.

Mondolfo R., y ZELLER, E., 1965: «La filosofia dei greci nel suo sviluppo storico», Firenze, La Nuova Italia, vol. IV, «Eraclito», a cura di R. MONDOLFO. 
Mossé, C., 1962: La fin de la démocratie atheniènne, Paris, 1962.

- 1967: «La conception du citoyen dans la Politique d'Aristote», Eirene, 6, 17-21.

- 1968, «Le role politique des armées dans la monde grec a l'époque classique», en Vernant, 221-230.

- 1969: La tyrannie dans la Grèce ancienne, Paris, Presses Universitaires de France.

Mulgan, R., 1991: «Aristotle's Analysis of Oligarchy and Democracy», en D. KEYT, y F. MiLLER, 307-22.

Mullhall, S., y SwIFT, A., 1992: Liberals and Communitarians, Oxford, Blackwell.

Nelson, E., 2004: The Greek Tradition in Republican Thought, Cambridge, U.P.

NEWMAN, W. L., 1892: «Aristotle's Classification of Forms of Government», Classical Review, 6, 289-293.

OBER, J., 2007: «I Besieged That Man: Democracy's Revolutionary Start», en Raaflaub-OberWallace, 2007, 83-104.

- 2008: «What the Ancient Greeks Can Tell Us About Democracy», Annual Review of Political Science, 11, 67-91.

Ollier, F., 1933: Le mirage spartiate, Paris, E. De Boccard.

Pateman, C., 1970: Participation and Democratic Theory, Cambridge, University Press.

Patzig, G., (ed.) 1990: Aristoteles’ «Politik», Göttingen, Vandenhoeck \& Ruprecht.

Platón: Rep: Res Publica, editada por J. Burnet, 1958, Oxford, Clarendon Press.

PHIL: Philebus, editado por A. DiEs, 1959, Paris, Les Belles Lettres.

Politicus: A. Dies (ed.), 1960, Paris, Les Belles Lettres.

Plutarco: Vitae, t. II, «Solon-Publicola-Themistocle-Camille», texte etabli et traduit par R. Flacelière, E. Chambry et M. Juneaux, 1961, Paris, Belles Lettres.

Polansky, R., 1991: «Aristotle on Political Change», en D. Keyt y F. Miller, 1991, 323-345.

Popper, K. R., 1966: The Open Society and its Enemies, 5. ' ed., 2 tomos, Londres, Routledge \& Kegan Paul.

RaAflaub, K. A., 1983: «Democracy, Oligarchy, and the Concept of "Free Citizen", in late FithCentury Athens», Political Theory, 11, 517-544.

RaAflaub, K. A.; Ober, J., y Wallace, R., 2007: Origins of Democracy in Ancient Greece, Berkeley-Los Angeles-London, University of California Press.

Raubitscheck, A. E., 1959: «Review: F. Sartori, Le eterie...», American Journal of Philology, vol. 80, núm. 1, 81-88.

Rawls, J., 1993: Political Liberalism, New York, Columbia U.P.

- 1999a: «The Idea of Public Reason Revisited», en The Law of Peoples, Cambridge, Mass.Londres, Harvard U.P., 131-180.

- 1999b: A Theory of Justice, Revised Edition, Cambridge, Mass., Belknap Press.

Rhodes, 1985: A Commentary on the Aristotelian Athenaion Politeia, Oxford, Clarendon Press.

Rinll, T. E., 1995: «Democracy Denied: Why Ephialtes Attacked the Areiopagus», Journal of Hellenic Studies, 115, 87-98.

RÖHRICH, W., 1980: Marx und die materialistische Staatstheorie, Darmstadt, Wissenschaftliche Buchgesell.

Rosler, A., 2005: Political Authority and Obligation in Aristotle, Oxford, Clarendon Press.

Rousseau, J. J., 1962: Du Contrat Social ou Principes du droit politique, Paris, Editions Garnier Frères.

SALmON, J., 1977: «Political Hoplites?», Journal of Hellenic Studies, 97, 84-101. 
SANDEL, M., 1982: Liberalism and the Limits of Justice, Cambridge, Cambridge U.P.

SChumpeter, J. A., 1952: Capitalism, Socialism, and Democracy, Londres, Allen \& Unwin.

SchÜtrumpF, E., 1996: Aristoteles Werke in deutscher Übersetzung, t. 9, III, Politik, Buch IV-VI, Berlin, Akademie Verlag.

Seager, R., 1963: «Herodotus and Ath. Pol., on the Date of Cleisthenes' Reforms», American Journal of Philology, 84, 287-289.

SEAley, R., 1974: «The Origins of "Demokratia"», California Studies in Classical Antiquity, 6, 253-295.

Sen, A., y Williams, B. (eds.) 1982: Utilitarianism and Beyond, Cambridge-London-New York, Cambridge UP.

Sidwick, H., 1892: «Aristotle's Classification of Forms of Government», Classical Review, 6, 141-144.

Sinclair T. A., 1961: A History of Greek Political Thought, London, Methuen.

Snodgrass, A. M., 1965: «The Hoplite Reform and History», Journal of Hellenic Studies, 85, 110-122.

STARK R., 1965: «Der Gesamtaufbau der aristotelischen Politik», en Fondat. Hardt, 1965, 1-36.

Steinmetz, P. (ed.), 1973: Schriften zu den Politika des Aristoteles, Hildesheim-New York, G. Olms.

Stroud, R., 1984: «The Gravestone of Socrates’ Friend, Lysis», Hesperia, 53, 355-360.

TAYlOR, Ch., 1982: «The Diversity of Goods», en SEN y Williams (eds.), 1982, 129-144.

- 1985: «Human Agency and Language», Philosophical Papers I, Cambridge, Cambridge U.P.

Tucídides: Historiae, edición crítica de H. STuart Jones y J. E. Powell, 2 t., Oxford, Clarendon Press, 1963.

- Histoire de la Guerre du Péloponnèse, J. DE Romilly (ed.), Paris, Les Belles Lettres, 1973.

Vernant J. P., 1966: Mythe et pensée chez les Grecs, Paris, Masperó.

- (ed.) 1968: Problèmes de la Guerre en Grèce ancienne, Paris-La Haye.

VIDAL-NAQUET, P., 1968: «La tradition de l'hoplite athénien», en Vernant, 161-80.

VLastos, G., 1946: «Solonian Justice», Classical Philology, 41, 65-83.

- 1947: «Equality and Justice in Early Greek Cosmologies», Classical Philology, 42, 156-178.

- 1953: «Isonomia», American Journal of Philology, 74, 337-366.

- 1964: «Isonomia politiké», ahora en Platonic Studies, Princeton, University Press, 1981.

WADE-GERY, H. T., 1933: «Studies in the Structure of Attic Society: II the Laws of Kleisthenes», Classical Quaterly, 27, 17-29.

Waldron, J., 1995: «The Wisdom of the Multitude: Some Reflections of Book 3, ch. 11 of Aristotle's Politics», Political Theory, 23, 563-584.

Wallace, R. W., 2007: «Revolutions and a New Order in Solonian Athens and Archaic Greece», en K. A. RAAFLAUB y otros, 49-82.

Weber, M., 1924: «Agrarverhältnisse im Altertum», en Gesammelte Aufsätze zur Sozial- und Wirtschaftsgeschichte, editados por J. WinCKELMANN, Tübingen, 1-288.

- 1971: Gesammelte Politische Schriften, J. Winckelmann (ed.), 3. a ed., Tübingen, Mohr.

- 1972: Wirtschaft und Gesellschaft, J. Winckelmann (ed.), 5. ${ }^{a}$ ed. Tübingen, Mohr.

- 1986: Gesammelte Aufsätze zur Religionssoziologie, 3 tomos, 8. a ed. Tübingen, Mohr.

WeIL, R., 1960: Aristote et l'histoire. Essai sur la «Politique», Paris, Klincksieck.

WheELER, M., 1951: «Aristotle's Análisis of the Nature of Political Struggle», American Journal of Philology, 72, 145-161. 
WilamowitZ-Moellendorf U. V., 1893: Aristoteles und Athen, reproducción fotomecánica (2. ${ }^{a}$ ed.), Berlin-Dublin-Zürich, Weidmann, 1966.

WILL, E., y otros, 1972: Le monde grec et l'orient (Peuples et civilisations: Histoire general), 2 tomos, Paris, Presses Universitaires de France.

ZunTZ, G., 1968: «Über Euripides' “Hiketiden”», en E. R. ScHWIngE (comp.), Euripides, Darmstadt, Wissenschaftliche Buchgesellschaft, 305-325. 